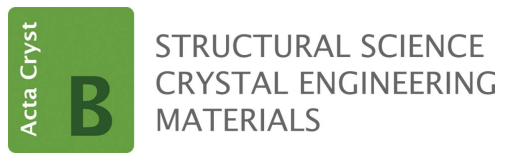

ISSN 2052-5206

Received 28 April 2020

Accepted 3 December 2020

Edited by R. B. Neder, University of ErlangenNürnberg, Germany

Dedicated to Ulrich Müller on the occasion of his 80th birthday.

Keywords: sodium alkoxide; powder data; solvate; isopropanol; Bärnighausen tree; PXRD.

CCDC references: $1943793 ; 1943794$; 1998221; 1998220; 1998219; 1998224; $1998225 ; 1998227$

Supporting information: this article has supporting information at journals.iucr.org/b
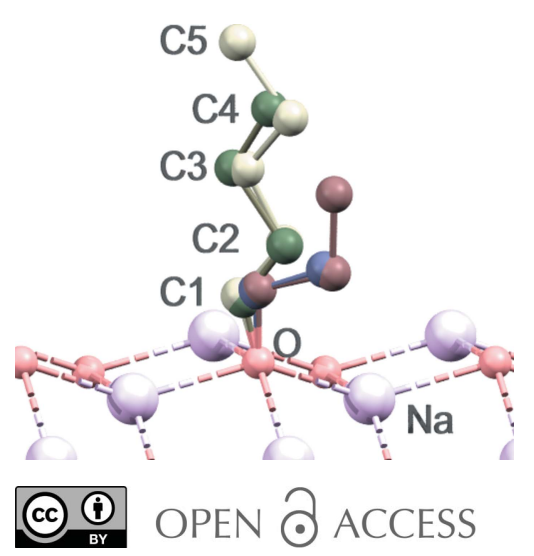

\section{Disordered sodium alkoxides from powder data: crystal structures of sodium ethoxide, propoxide, butoxide and pentoxide, and some of their solvates}

\author{
Maurice Beske, ${ }^{\mathrm{a}, \mathrm{b}}$ Stephanie Cronje, ${ }^{\mathrm{a}}$ Martin U. Schmidt ${ }^{\mathrm{a} *}$ and Lukas Tapmeyer $^{\mathrm{a}}$ \\ anstitut für Anorganische und Analytische Chemie, Goethe-Universität, Max-von-Laue-Strasse 7, 60438 Frankfurt am \\ Main, Germany, and ${ }^{\mathbf{b}}$ Department Chemie, Johannes Gutenberg-Universität Mainz, Duesbergweg 10-14, 55128 Mainz, \\ Germany. *Correspondence e-mail: m.schmidt@chemie.uni-frankfurt.de
}

The crystal structures of sodium ethoxide (sodium ethanolate, $\mathrm{NaOEt}$ ), sodium $n$-propoxide (sodium $n$-propanolate, $\mathrm{NaO}^{n} \mathrm{Pr}$ ), sodium $n$-butoxide (sodium $n$-butanolate, $\mathrm{NaO}^{n} \mathrm{Bu}$ ) and sodium $n$-pentoxide (sodium $n$-amylate, $\mathrm{NaO}^{n} \mathrm{Am}$ ) were determined from powder X-ray diffraction data. NaOEt crystallizes in space group $P \overline{4} 2_{1} m$, with $Z=2$, and the other alkoxides crystallize in $P 4 / n m m$, with $Z=2$. To resolve space-group ambiguities, a Bärnighausen tree was set up, and Rietveld refinements were performed with different models. In all structures, the $\mathrm{Na}$ and $\mathrm{O}$ atoms form a quadratic net, with the alkyl groups pointing outwards on both sides (anti-PbO type). The alkyl groups are disordered. The disorder becomes even more pronounced with increasing chain length. Recrystallization from the corresponding alcohols yielded four sodium alkoxide solvates: sodium ethoxide ethanol disolvate ( $\mathrm{NaOEt} \cdot 2 \mathrm{EtOH})$, sodium $n$-propoxide $n$-propanol disolvate $\left(\mathrm{NaO}^{n} \mathrm{Pr} \cdot 2^{n} \mathrm{PrOH}\right)$, sodium isopropoxide isopropanol pentasolvate $\left(\mathrm{NaO}{ }^{i} \operatorname{Pr} \cdot 5^{i} \mathrm{PrOH}\right)$ and sodium tert-amylate tert-amyl alcohol monosolvate $\left(\mathrm{NaO}{ }^{t} \mathrm{Am} \cdot{ }^{t} \mathrm{AmOH},{ }^{t} \mathrm{Am}=2\right.$-methyl-2-butyl). Their crystal structures were determined by single-crystal X-ray diffraction. All these solvates form chain structures consisting of $\mathrm{Na}^{+},-\mathrm{O}^{-}$and $-\mathrm{OH}$ groups, encased by alkyl groups. The hydrogen-bond networks diverge widely among the solvate structures. The hydrogen-bond topology of the ${ }^{i} \mathrm{PrOH}$ network in $\mathrm{NaO}{ }^{i} \mathrm{Pr} \cdot 5^{i} \mathrm{PrOH}$ shows branched hydrogen bonds and differs considerably from the networks in pure crystalline ${ }^{i} \mathrm{PrOH}$.

\section{Introduction}

\subsection{General}

Even today, there are simple chemical compounds for which the crystal structures are not known. The reasons for this deficiency in knowledge include synthetic difficulties, complex phase behaviour, instability in a vacuum and under an inert atmosphere, lack of single crystals, unusual or ambiguous space groups, and disorder. All these difficulties can be found in sodium alkoxides (sodium alcoholates) $\mathrm{NaOR}$ and their solvates $\mathrm{NaO} R \cdot x R \mathrm{OH}$, with $R$ being a lower alkyl group. In principle, these compounds can be easily prepared by the reaction of sodium with the corresponding alcohol. However, in practice, the synthesis of the pure phases presents some obstacles. For example, when sodium is reacted with ethanol and the ethanol excess is removed in vacuo, a white powder remains. This powder turns into a liquid within a few minutes under argon. Further evaporation under vacuum results in a powder, which again liquefies under argon. Finally, a white residue is obtained, which consists of a mixture of two to four different phases, including sodium ethoxide ( $\mathrm{NaOEt}$ ) and its ethanol disolvate NaOEt.2EtOH (Beske et al., 2020). Phase- 
pure NaOEt is only obtained after a few hours of evaporation under vacuum at $50{ }^{\circ} \mathrm{C}$. The initially formed solvate NaOEt. $2 \mathrm{EtOH}$ decomposes under vacuum, and even under dry argon, and is stable only in the presence of ethanol vapour. Similar difficulties are observed for other sodium alkoxides (see below). Additionally, all the compounds are very sensitive to moisture.

In industry, as well as in the laboratory, sodium alkoxides are widely used as bases and as reagents in organic synthesis. This is not only true for NaOEt, but also for other alkoxides. For example, sodium tert-amylate (sodium 2-methyl-2-butoxide, $\mathrm{NaO}^{t} \mathrm{Am}$ ) is used industrially on a multi-ton scale in the synthesis of diketopyrrolopyrrole pigments, which today are the most commonly used pigments for red car coatings (Hunger \& Schmidt, 2018).

\subsection{Historical notes on $\mathrm{NaOEt}$}

Sodium ethoxide was synthesized as early as 1837 by Liebig (Liebig, 1837; Beske et al., 2020). Since ethanol was considered the hydrate of ethyl ether $\left(2 \mathrm{EtOH} \hat{=} \mathrm{Et}_{2} \mathrm{O} \cdot \mathrm{H}_{2} \mathrm{O}\right)$, sodium ethoxide was regarded as an adduct of diethyl ether and sodium oxide, which actually corresponds to the correct stoichiometry: $\mathrm{Et}_{2} \mathrm{O} \cdot \mathrm{Na}_{2} \mathrm{O} \hat{=} 2 \mathrm{NaOEt}$. Correspondingly, the name 'Aethernatron' (Geuther, 1868a,b) was used besides the names 'Natriumalkoholat' (Geuther, 1859) and 'Natriumäthylat' (Wanklyn, 1869).

Many years later, the crystal structure of sodium methoxide $(\mathrm{NaOMe})$ was determined from powder X-ray diffraction (PXRD) data (Weiss, 1964). Surprisingly, the crystal structure of NaOEt was not determined, although it is isostructural with $\mathrm{NaOMe}$. It would have been an easy task to index the powder pattern of NaOEt manually, because $\mathrm{NaOEt}$ crystallizes in the tetragonal crystal system, and the lattice parameters $a$ and $b$ of $\mathrm{NaOEt}$ are almost identical to those in NaOMe.

In 1976, the PXRD patterns of NaOEt and NaOEt-2EtOH were published in an article devoted to the thermal stability of alkali ethoxides (Blanchard et al., 1976). Again, no attempt was made to index the powder data.

As much as 30 years later, the powder data of NaOEt and sodium $n$-propoxide $\left(\mathrm{NaO}^{n} \mathrm{Pr}\right)$ were indexed, but the crystal structures remained indeterminate (Chandran et al., 2006). Finally, we determined the crystal structure of $\mathrm{NaOEt}$ from powder data, and of NaOEt.2EtOH from single-crystal data a few months ago. The crystal structures were recently briefly described in a chemical journal (Beske et al., 2020), without any discussion on the ambiguity of the space group or of the crystal symmetry. Here, we report a full discussion of the ambiguities of the space group of $\mathrm{NaOEt}$, including a Bärnighausen tree of the possible space groups and their subgroups.

\subsection{Previous work on other alkoxides}

The first determined crystal structure of a sodium alkoxide was that of $\mathrm{NaOMe}$ (Weiss, 1964). $\mathrm{NaOMe}$ is isotypical to LiOMe (Wheatley, 1961) and crystallizes in a layer structure in the space group $P 4 / n m m$, with $Z=2$.
Potassium methoxide, KOMe, crystallizes in the same space group type as $\mathrm{NaOMe}$, but the structure is different: whereas the $\mathrm{Na}^{+}$ions in NaOEt are coordinated to four $\mathrm{O}$ atoms, the $\mathrm{K}^{+}$ions in $\mathrm{KOMe}$ are coordinated to five $\mathrm{O}$ atoms in a squarepyramidal geometry (Weiss, 1963; Weiss \& Alsdorf, 1970). The $\mathrm{O}$ atom is surrounded by five $\mathrm{K}^{+}$ions and the methyl group has a distorted octahedral geometry. A similar structure was found for partially hydrolysed $\mathrm{NaOMe}$ with the composition $\mathrm{Na}(\mathrm{OMe})_{1-x}(\mathrm{OH})_{x}$, with $x \approx 1 / 3$ (Weiss, 1964).

Sodium tert-butoxide, $\mathrm{NaO}^{t} \mathrm{Bu}$, exists in two polymorphic forms. Both structures were determined by single-crystal $\mathrm{X}$-ray diffraction. One of the phases consists of hexamers and crystallizes in the space group $P 2_{1} 2_{1} 2_{1}$, with $Z=20$, with five hexamers per asymmetric unit (Østreng et al., 2014). The other phase contains a 1:1 mixture of hexamers and nonamers in the space group $R \overline{3}$, with $Z=6$, with 90 formula units per unit cell (Greiser \& Weiss, 1977; Davies et al., 1982; Nekola et al., 2002). Accordingly, both phases have quite large unit cells.

\subsection{Solvates}

Sodium alkoxides can form solvates with their corresponding alcohols. Already in 1837 Liebig had prepared an ethanol solvate of NaOEt by the reaction of sodium with ethanol at $50^{\circ} \mathrm{C}$ and subsequent cooling of the solution to room temperature, whereupon the mixture turned into a solid (Liebig, 1837). However, Liebig apparently did not recognize this precipitate as a solvate. In 1868, Scheitz determined the composition of this solvate as NaOEt.2EtOH (Geuther, 1868a). This result was confirmed by Marsh (Geuther, 1868b), whereas Wanklyn (1869) determined the composition to be $\mathrm{NaOEt} \cdot 3 \mathrm{EtOH}$. In 1880, Frölich again found a composition of NaOEt-2EtOH using a different method (Geuther \& Frölich, 1880). Lescoeur (1895) measured the vapour pressure during slow evaporation of a suspension of NaOEt in $\mathrm{EtOH}$ and observed that the vapour pressure did not change between compositions of $\mathrm{NaOEt} \cdot 1.7 \mathrm{EtOH}$ and nearly pure $\mathrm{NaOEt}$, and thus concluded that the solvate had the composition $\mathrm{NaOEt} \cdot 2 \mathrm{EtOH}$.

The crystal morphology of NaOEt-2EtOH was described as 'völlig durchsichtige farblose nadelförmige Krystalle' (fully transparent, colourless, needle-like crystals) (Geuther, 1868a).

Geuther \& Frölich (1880) also described a solvate with a composition of $\mathrm{NaO}^{n} \mathrm{Pr} \cdot 2^{n} \mathrm{PrOH}$. A ${ }^{t} \mathrm{AmOH}$ solvate of $\mathrm{NaO}^{t} \mathrm{Am}$ was mentioned by Friedrich et al. (1999), but no composition as given.

The solvates are thermally remarkably stable. NaOEt. $2 \mathrm{EtOH}$ must be heated at ambient pressure to $200^{\circ} \mathrm{C}$ and $\mathrm{NaO}{ }^{n} \operatorname{Pr} \cdot 2^{n} \mathrm{PrOH}$ even to $220^{\circ} \mathrm{C}$ before the pure solvent-free alkoxides are obtained (Geuther \& Frölich, 1880). Solventfree NaOEt is also quite stable. According to differential thermal analysis, the decomposition starts at $50^{\circ} \mathrm{C}$, but this decomposition is very slow and occurs over a large temperature range. Finally, at $310^{\circ} \mathrm{C}$ the decomposition 'adopts an explosive character' ('prendre un charactère explosif'; Blanchard et al., 1976). 
Crystals of the solvates of $\mathrm{NaO}^{n} \mathrm{Pr}, \mathrm{NaO}^{i} \mathrm{Pr}$ and $\mathrm{NaO}^{t} \mathrm{Am}$ do form easily when sodium is reacted with the corresponding alcohols and the solution is subsequently carefully evaporated. However, no structure of any sodium alkoxide solvate was determined between 1837 and 2019 (Beske et al., 2020). The reason might be the pronounced sensitivity of the crystals to moisture, air, vacuum and dry inert gas.

\subsection{Work in this article}

In this article, we describe the synthesis, structure determination, crystal structure and disorder of $\mathrm{NaOEt}, \mathrm{NaO}^{n} \mathrm{Pr}$, $\mathrm{NaO}^{n} \mathrm{Bu}$ and $\mathrm{NaO}^{n} \mathrm{Am}$, and of the solvates NaOEt$\cdot 2 \mathrm{EtOH}$, $\mathrm{NaO}{ }^{n} \mathrm{Pr} \cdot 2^{n} \mathrm{PrOH}, \mathrm{NaO}{ }^{i} \mathrm{Pr} \cdot 5^{\mathrm{i}} \mathrm{PrOH}$ and $\mathrm{NaO}^{t} \mathrm{Am} \cdot{ }^{t} \mathrm{AmOH}$. The structures of the solvent-free compounds were determined by PXRD and the structures of the solvates by single-crystal $\mathrm{X}$-ray analyses. In the cases of $\mathrm{NaOEt}$ and $\mathrm{NaO}^{n} \mathrm{Pr}$, the spacegroup symmetry was ambiguous, and the corresponding symmetry relationships were elaborated using a Bärnighausen tree.

\section{Experimental details}

\subsection{Syntheses}

All synthetic procedures were performed under an argon atmosphere using Schlenk techniques. All alcohols, as well as toluene, were dried over sodium and freshly distilled.

2.1.1. NaOEt. $0.34 \mathrm{~g}(15 \mathrm{mmol})$ of sodium were added to $10 \mathrm{ml}(170 \mathrm{mmol})$ of ethanol. The mixture was allowed to react for $30 \mathrm{~min}$ at room temperature. The obtained solution was heated to $50^{\circ} \mathrm{C}$ and the excess ethanol was removed under vacuum. The resulting solid product was evaporated at $50{ }^{\circ} \mathrm{C}$ under vacuum for $3 \mathrm{~h}$, gently crushed with a glass rod and again evaporated for one additional hour under the same conditions. A phase-pure white powder of NaOEt was obtained.

2.1.2. $\mathrm{NaO}^{n} \mathrm{Pr}, \mathrm{NaO}^{n} \mathrm{Bu}$ and $\mathrm{NaO}^{n} \mathrm{Am} . \mathrm{NaO}^{n} \mathrm{Pr}, \mathrm{NaO}{ }^{n} \mathrm{Bu}$ and $\mathrm{NaO}^{n} \mathrm{Am}$ were synthesized in a similar manner to $\mathrm{NaOEt}$. Details are given in the supporting information.

2.1.3. NaOEt.2EtOH. $0.34 \mathrm{~g}$ of sodium $(15 \mathrm{mmol})$ were added to $5.0 \mathrm{ml}(85 \mathrm{mmol})$ of ethanol. After reacting for $30 \mathrm{~min}$, a gel was obtained. This gel was stored for three months at room temperature, resulting in a pale-brown solution and colourless needles of $\mathrm{NaOEt} \cdot 2 \mathrm{EtOH}$ with a size of up to $1 \mathrm{~mm}$.

2.1.4. $\mathrm{NaO}^{n} \mathrm{Pr} \cdot 2^{n} \mathrm{PrOH}, \mathrm{NaO}^{i} \mathrm{Pr} \cdot 5^{i} \mathrm{PrOH}$ and $\mathrm{NaO}^{t} \mathrm{Am}$. ${ }^{t} \mathrm{AmOH}$. Syntheses and crystal growth of these compounds resembled the procedure used for $\mathrm{NaOEt} \cdot 2 \mathrm{EtOH}$. Details are given in the supporting information.

\subsection{Pre-characterization}

The stoichiometry of the solvent-free alkoxides was confirmed by decomposition experiments with $\mathrm{HCl}$, which verified their stoichiometry. Details are reported in the supporting information. For the solvates, this analysis could not be performed, because the solvates decomposed rapidly when removed from their alcoholic mother liquor.

\subsection{Powder X-ray diffraction (PXRD)}

For the PXRD studies, the samples were sealed in glass capillaries with a $1.0 \mathrm{~mm}$ diameter. The PXRD patterns were measured in transmission mode on a Stoe Stadi-P diffractometer equipped with a $\mathrm{Ge}(111)$ monochromator and a linear position-sensitive detector. The capillaries were spun during the measurements. All measurements were performed at room temperature, using $\mathrm{Cu} K \alpha_{1}$ radiation $(\lambda=1.5406 \AA)$, with a $2 \theta$ range of $2-100^{\circ}\left(2-80^{\circ}\right.$ for $\left.\mathrm{NaOEt}\right)$.

\subsection{Structure determination from powder data}

The crystal structures of the solvent-free alkoxides NaOEt, $\mathrm{NaO}^{n} \mathrm{Pr}, \mathrm{NaO}^{n} \mathrm{Bu}$ and $\mathrm{NaO}^{n} \mathrm{Am}$ were determined from PXRD data. The powder data were indexed with the program DICVOL (Boultif \& Louër, 1991) within the program package DASH (David et al., 2006). The structures were solved by the real-space method with simulated annealing using $D A S H$. Subsequently, Rietveld refinements were performed using TOPAS (Coelho, 2018).

For all four compounds indexing led to a tetragonal unit cell with $Z=2$. The systematic extinction indicated $P 4 / \mathrm{n}, P 4 / \mathrm{nmm}$ and $P \overline{4} 2{ }_{1} m$ as possible space groups. The structures were successfully solved in $P 4 / \mathrm{nmm}$ and $P \overline{4} 2_{1} m$, using two fragments, an $\mathrm{Na}$ atom and a rigid alkoxide moiety. The $\mathrm{Na}$ atom was placed on the special position, which allowed a distorted tetrahedral coordination [Wyckoff position $2 a\left(\frac{3}{4}, \frac{1}{4}, 0\right)$ in $P 4 / \mathrm{nmm}$ origin choice $2 ; 2 a(0,0,0)$ in $P \overline{4} 2_{1} m$ ], as explained in §3.1. The alkoxide fragment was placed on a general position, with an occupancy of 0.125 (in $P 4 / \mathrm{nmm}$ ) or 0.25 (in $P \overline{4} 2_{1} m$ ). In the resulting structures, the $\mathrm{C}$ atoms moved close to a site with ..m symmetry, and were subsequently placed on this site, resulting in an occupancy of 0.25 (in $P 4 / \mathrm{nmm}$ ) or 0.5 (in $P \overline{4} 2_{1} m$ ). In the Rietveld refinements of $\mathrm{NaOEt}$, restraints were only necessary for the $\mathrm{H}$ atoms. For $\mathrm{NaO}^{n} \mathrm{Pr}, \mathrm{NaO}^{n} \mathrm{Bu}$ and $\mathrm{NaO}^{n} \mathrm{Am}$, additional restraints were applied to the $\mathrm{O}-\mathrm{C}$ and $\mathrm{C}-\mathrm{C}$ bond lengths, and to the $\mathrm{O}-\mathrm{C}-\mathrm{C}$ and $\mathrm{C}-\mathrm{C}-\mathrm{C}$ bond angles. All $\mathrm{H}$ atoms were refined using restraints on the bond lengths and angles with quite high weights. Further details of the Rietveld refinements are given in the supporting information.

Note that there are two different origin choices for $P 4 / \mathrm{nmm}$. Origin choice 2 (origin on $\overline{1}$ ) was used for the structure solution, due to the requirements of $D A S H$. In contrast, the origin choice 1 (origin on $\overline{4}$, as in $P \overline{4} 2_{1} m$ ) was used for the Bärnighausen tree.

\subsection{Single-crystal X-ray diffraction}

A single crystal of NaOEt-2EtOH was placed in a sealed glass capillary and data were collected at $-38(2){ }^{\circ} \mathrm{C}$. Single crystals of $\mathrm{NaO}^{n} \mathrm{Pr} \cdot 2^{n} \mathrm{PrOH}$ and $\mathrm{NaO}{ }^{i} \mathrm{Pr} \cdot 5^{i} \mathrm{PrOH}$ were mounted by freezing them in a drop of oil and their data collected under a cold nitrogen stream at $-100(2){ }^{\circ} \mathrm{C}$ using an Oxford Cryosystems cryostream device. Crystals of $\mathrm{NaO}^{t} \mathrm{Am}$. ${ }^{t} \mathrm{AmOH}$ were sealed in a glass capillary under paraffin oil (dried with $\mathrm{Na}$ ) and their data collected at room temperature. 
Single-crystal data were collected on a Bruker SMART APEX three-circle diffractometer equipped with an Incoatec $\mathrm{I} \mu \mathrm{S} \mathrm{Cu}$ microfocus source with mirror optics and an APEX II CCD detector. The software package APEX3 (Bruker, 2015) was used for data collection and data reduction. The structures were solved by direct methods with SHELXT (Sheldrick, 2015a) and refined with SHELXL (Sheldrick, 2015b). All non$\mathrm{H}$ atoms, except for disordered $\mathrm{C}$ atoms, were refined anisotropically. Disordered $\mathrm{C}$ atoms were refined isotropically. $\mathrm{H}$ atoms bonded to $\mathrm{C}$ atoms were treated with the riding model. In the case of NaOEt-2EtOH and $\mathrm{NaO}^{n} \mathrm{Pr} \cdot 2^{n} \mathrm{PrOH}$, all $\mathrm{OH}$ protons could be located by Fourier synthesis. In $\mathrm{NaO}^{i} \mathrm{Pr}$. $5^{i} \mathrm{PrOH}$, it was not possible to detect which of the four ligands coordinating to the $\mathrm{Na}^{+}$ion is the ${ }^{i} \mathrm{PrO}^{-}$anion, and which are the three ${ }^{i} \mathrm{PrOH}$ molecules. (The $\mathrm{H}$ atom could not be located, all $\mathrm{Na}-\mathrm{O}$ bonds were of a similar length, all $\mathrm{C}-\mathrm{O}$ bonds were of similar length, and in addition no decision could be made based on the size of the angles; furthermore, there is a twofold axis through the $\mathrm{Na}^{+}$ion, hence there are always pairs of symmetrically equivalent ligands.) All $\mathrm{O}$ atoms of $\mathrm{NaO}^{i} \mathrm{Pr} \cdot 5^{i} \mathrm{PrOH}$ are part of a complex hydrogen-bond network, and obviously the $\mathrm{H}$ atoms are disordered within this network. Therefore, for each $\mathrm{Na}^{+}$cation, $\mathrm{H}$ atoms with occupancies of 0.75 were placed at all four $\mathrm{O}$ atoms connected to the $\mathrm{Na}^{+}$cation. For $\mathrm{NaO}^{t} \mathrm{Am} \cdot{ }^{t} \mathrm{AmOH}$, the electron density indicates that the $\mathrm{H}$ atoms of the $\mathrm{OH}$ groups are located along hydrogen bonds. However, the limited data quality did not allow an unrestrained refinement of the positions of these $\mathrm{H}$ atoms. According to the charge compensation, the $\mathrm{H}$ atoms should be disordered, too.

The single crystals of $\mathrm{NaO}^{i} \mathrm{Pr} \cdot 5^{i} \mathrm{PrOH}$ are highly sensitive; they decompose within seconds except when they are kept in their mother liquor under an inert atmosphere. Therefore, only rather poor diffraction data could be obtained. Correspondingly, a large number of restraints had to be used in the refinement. The disordered $\mathrm{C}$ atoms were refined isotropically, with restraints on the $\mathrm{C}-\mathrm{C}$ and $\mathrm{C}-\mathrm{O}$ bond lengths. The ordered $\mathrm{C}$ atoms were refined anisotropically, but their anisotropic displacement parameters were restrained to be similar to those of neighbouring atoms.

\section{Results and discussion}

\subsection{Space group and disorder of sodium ethoxide (NaOEt)}

Sodium ethoxide is difficult to obtain as a pure phase. The reaction of sodium with ethanol, with subsequent evaporation at room temperature under vacuum or evaporation at the boiling point at ambient pressure, results in a mixture of two to four phases, including NaOEt and NaOEt-2EtOH. Evaporation under vacuum at $50^{\circ} \mathrm{C}$ for several hours leads to phasepure NaOEt. Nevertheless, most of our recorded powder patterns were contaminated by traces of other phases.

The powder pattern of NaOEt could be indexed with a tetragonal unit cell, with $a=b=6.2, c=9.1 \AA$ and $V=352 \AA^{3}$. According to Hofmann's volume increments (Hofmann, 2002), the unit-cell volume corresponds to $Z=4$. The systematic extinctions pointed to the space group P4/nbm. Further experiments revealed that some of the weak peaks in the powder pattern were actually caused by foreign phases. The pattern of the phase-pure NaOEt could be indexed with a unit cell of half of the initial volume, with $a=b=4.41, c=$ $9.07 \AA, \alpha=\beta=\gamma=90^{\circ}, V=176.4 \AA^{3}$ and $Z=2$.

The systematic extinctions lead to the extinction symbol $P n--$, which corresponds to the space group $P 4 / n$ or $P 4 / n m m$ (Hahn, 2005). In P4/nmm, the structure could be solved without difficulty by the real-space method with simulated annealing using the program DASH (David et al., 2006). The unit cell contains two formula units. In $P 4 / \mathrm{nmm}$ there are three different Wyckoff positions with a multiplicity of two: positions $2 a$ and $2 b$ with site symmetry $\overline{4} m 2$, and $2 c$ with site symmetry $4 \mathrm{~mm}$. A tetrahedral coordination of the $\mathrm{Na}^{+}$ion agrees with a $\overline{4} m 2$ site symmetry. Correspondingly, the $\mathrm{Na}^{+}$ion

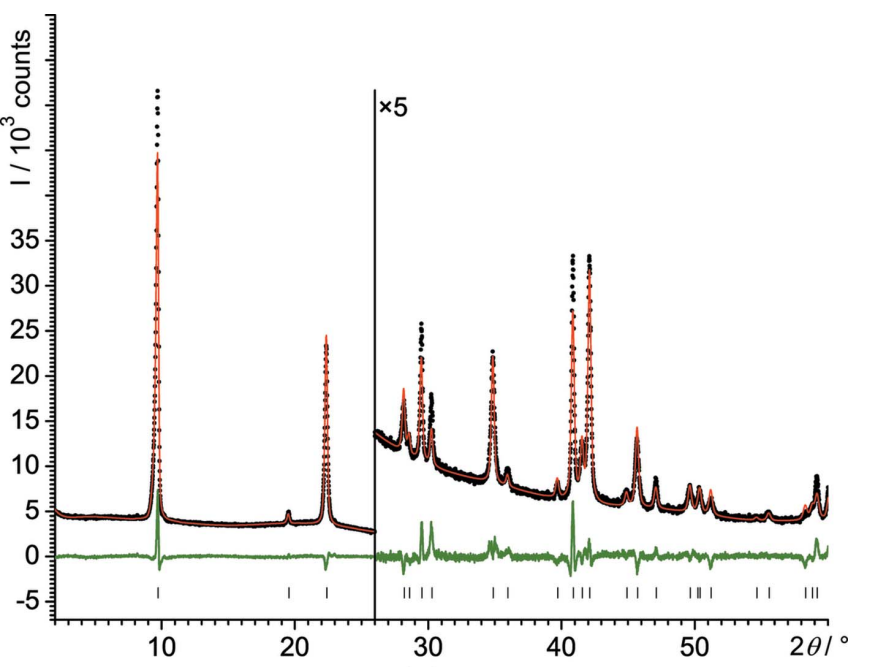

(a)

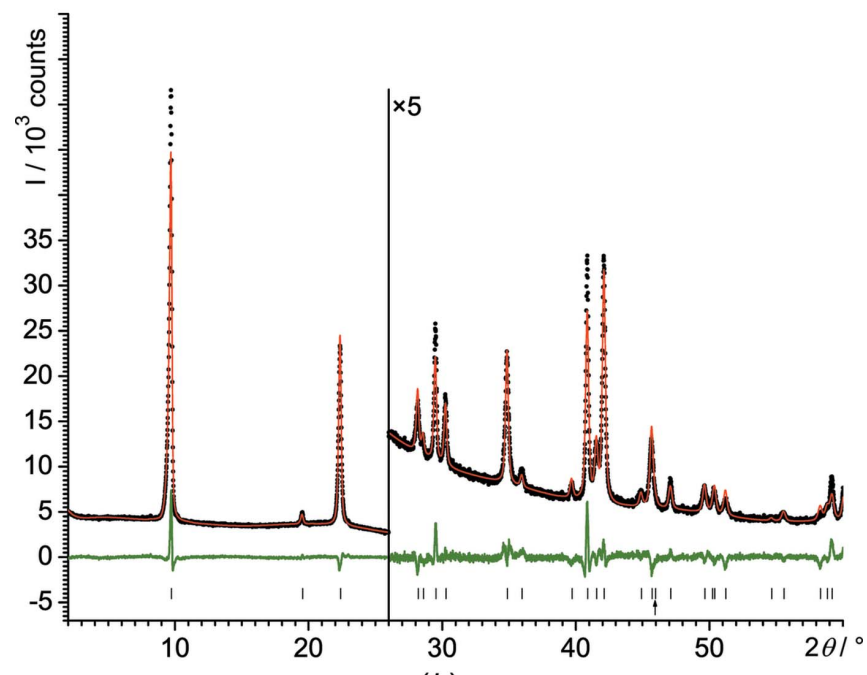

(b)

Figure 1

Rietveld plots of NaOEt performed in different space groups under identical conditions, i.e. (a) $P 4 / n m m$ and (b) $P \overline{4} 2_{1} m$. Experimental data are shown as black dots and simulated data as a red line, with the difference curve in green below. The vertical tick marks denote the reflection positions. The small arrow in $(b)$ denotes the 210 reflection, which is extinct in $P 4 / n m m$, but present in $P \overline{4} 2_{1} m$. 
Table 1

Rietveld refinement of NaOEt in $P 4 / \mathrm{nmm}$ and $P \overline{4} 2_{1} m$ under identical conditions, with restrained $\mathrm{H}$-atom positions and a $2 \theta$ range of $2-60^{\circ}$.

The values marked by a ' are background-subtracted values. $N$ (param) is the number of structural parameters, including the occupancy parameter.

\begin{tabular}{lccc}
\hline & & & $P \overline{4} 2_{1} m$ with both \\
& $P 4 / n m m$ & $P \overline{4} 2_{1} m$ & orientations of Et \\
\hline$R_{\mathrm{wp}}(\%)$ & 4.320 & 4.146 & 4.149 \\
$R_{\mathrm{wp}}{ }^{\prime}(\%)$ & 16.98 & 16.30 & 16.30 \\
$R_{\mathrm{p}}(\%)$ & 3.205 & 3.122 & 3.126 \\
$R_{\mathrm{p}}{ }^{\prime}(\%)$ & 18.21 & 17.74 & 17.75 \\
Goodness-of-fit & 2.016 & 1.935 & 1.936 \\
$N($ param) & 13 & 13 & $13+1$ (occupancy) \\
Occupancy of & 0.25 (fixed) & 0.5 (fixed) & 0.476 (6):0.024 (6) \\
$\quad$ the ethyl group & & &
\end{tabular}

was set at position $2 a$. A rigid $\mathrm{C}_{2} \mathrm{H}_{5} \mathrm{O}$ fragment was placed on the general position $(16 k)$ with an occupancy of 0.125 . The best solution was found in about 10 out of 25 runs and had a good profile- $\chi^{2}$ value of 7.26. The $\mathrm{O}$ atom was found very close to the $4 \mathrm{~mm}$ site (Wyckoff position $2 \mathrm{c}$ ), hence it could be set at this site. The ethyl group is disordered around the $4 \mathrm{~mm}$ site. The two $\mathrm{C}$ atoms could be situated on the general position $(16 k)$, resulting in eightfold disorder, or on mirror planes parallel to (100) and (010) (Wyckoff position $8 i$, site symmetry .m.), or on diagonal mirror planes (Wyckoff position $8 j$, site symmetry ..m), each with fourfold disorder.

The structure was refined by the Rietveld ${ }^{\mathbf{1}}$ method (Loopstra \& Rietveld, 1969) with TOPAS, with the $\mathrm{C}$ atoms on the general position $(16 k)$. During the refinement, the $\mathrm{C}$ atoms moved close to the diagonal mirror planes. Correspondingly, they were set to the sites $8 j(. . m)$. The refinements converged with good $R$ values (Table 1 ) and smooth difference curves (Fig. 1a). The ethyl groups are fourfold disordered around the fourfold axes, see Fig. 2(a). A corresponding structure was also found for lithium methoxide (LiOMe) (Wheatley, 1961) and sodium methoxide (NaOMe) (Weiss, 1964).

A symmetry analysis revealed that in the subgroup $P \overline{4} 2_{1} m$ the ethyl groups would have a twofold disorder only. $P \overline{4} 2{ }_{1} m$ is a translationengleiche subgroup of $P 4 / \mathrm{nmm}$ (Wondratschek \& Müller, 2004; Aroyo, 2016) [see Fig. 2(b)]. These two space groups are difficult to distinguish from each other using the systematic extinctions in PXRD. P4/nmm requires the reflection condition $h k 0: h+k=2 n$, whereas $P \overline{4} 2{ }_{1} m$ requires only $h 00: h=2 n$ and $0 k 0: k=2 n$ (Hahn, 2005). However, in the $2 \theta$ range up to $60^{\circ}$, the powder pattern contains only one reflection, which is systematically absent in $P 4 / \mathrm{nmm}$ but can be present in $P \overline{4} 2_{1} m$. This is the 210 reflection, which has an intensity of close to zero (see Fig. 1b). Hence, an examination of the systematic extinctions left the space group ambiguous.

As a test for the space group, Rietveld refinements were performed in $P 4 / \mathrm{nmm}$ and $P \overline{4} 2_{1} m$ under identical conditions (identical treatment of background, profile parameters, anisotropic peak broadening, etc.). It is an interesting peculiarity that the number of structural parameters is identical in

\footnotetext{
${ }^{\mathbf{1}}$ For a discussion on the name 'Rietveld method' versus the name 'Loopstra method', see van Laar \& Schenk (2018).
}

both space groups, which is a very rare case for an organic crystal structure in a group-subgroup relationship. Hence, the resulting confidence values of both space groups can be compared directly. The difference in the $R$ values is slightly in favour of $P \overline{4} 2_{1} m$ (see Table 1). The Rietveld plots are very similar, just the 111 reflection at $2 \theta=30.28^{\circ}$ is significantly better fitted in $P \overline{4} 2_{1} m$ (see Fig. 1).

In both space groups, the structure is very similar, except for the disorder of the ethyl groups. In $P 4 / \mathrm{nmm}$ the ethyl group is disordered around a fourfold axis, which changes to a twofold axis in $P \overline{4} 2_{1} m$ [see Figs. $2(a)$ and $2(b)$ ].

As a further test for the space group, a Rietveld refinement was performed in the space group $P \overline{4} 2_{1} m$ with two sets of ethyl groups, one in the position $x, x+\frac{1}{2}, z$ (Wyckoff position $8 j$ ) according to the $P \overline{4} 2_{1} m$ structure, and the other on the posi-

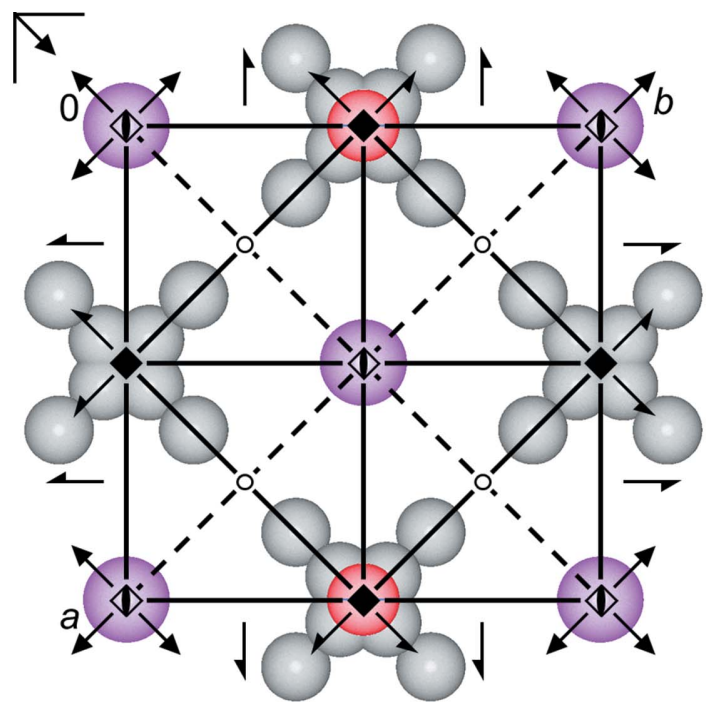

(a)

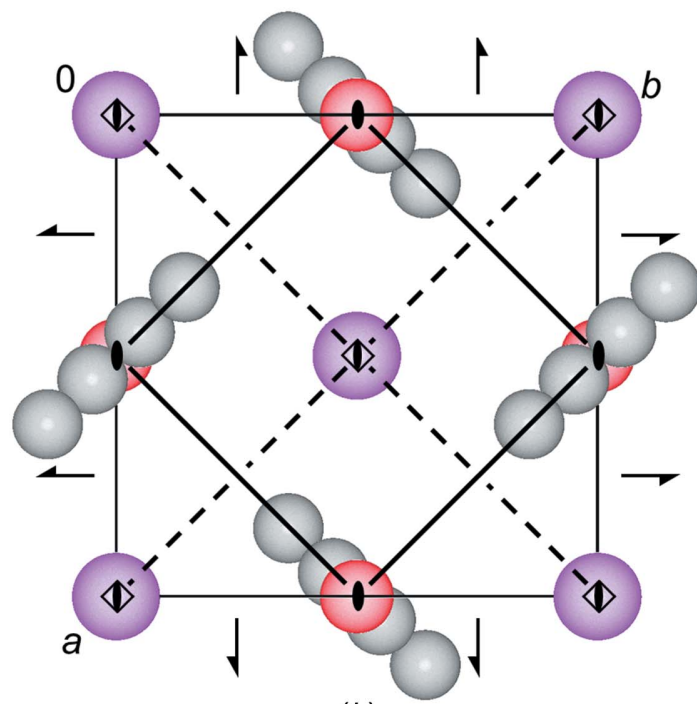

(b)

Figure 2

Structural models of NaOEt in (a) P4/nmm (origin choice 1) and (b) $P \overline{4} 2{ }_{1} m$. Colour key: Na violet, $\mathrm{O}$ red and $\mathrm{C}$ grey (disordered). $\mathrm{H}$ atoms have been omitted for clarity. The view direction is [001]. The crystallographic symmetry elements are included. 
tion $-x, x+\frac{1}{2}, z$, which is occupied in $P 4 / n m m$, but not in $P \overline{4} 2_{1} m$ (see Fig. 2). The occupancies of both sets were set at $p$ and $\frac{1}{2}-p$. For $P \overline{4} 2{ }_{1} m, p$ would be $\frac{1}{2}$ and for $P 4 / n m m, p$ is $\frac{1}{4}$. The parameter $p$ refined to $0.476(6)$. This value and the similarity of the $R$ values between this refinement and the refinement in $P \overline{4} 2{ }_{1} m$ clearly indicate that, within the limitations of the powder data, the correct space group is $P \overline{4} 2_{1} m$ instead of P4/nmm.

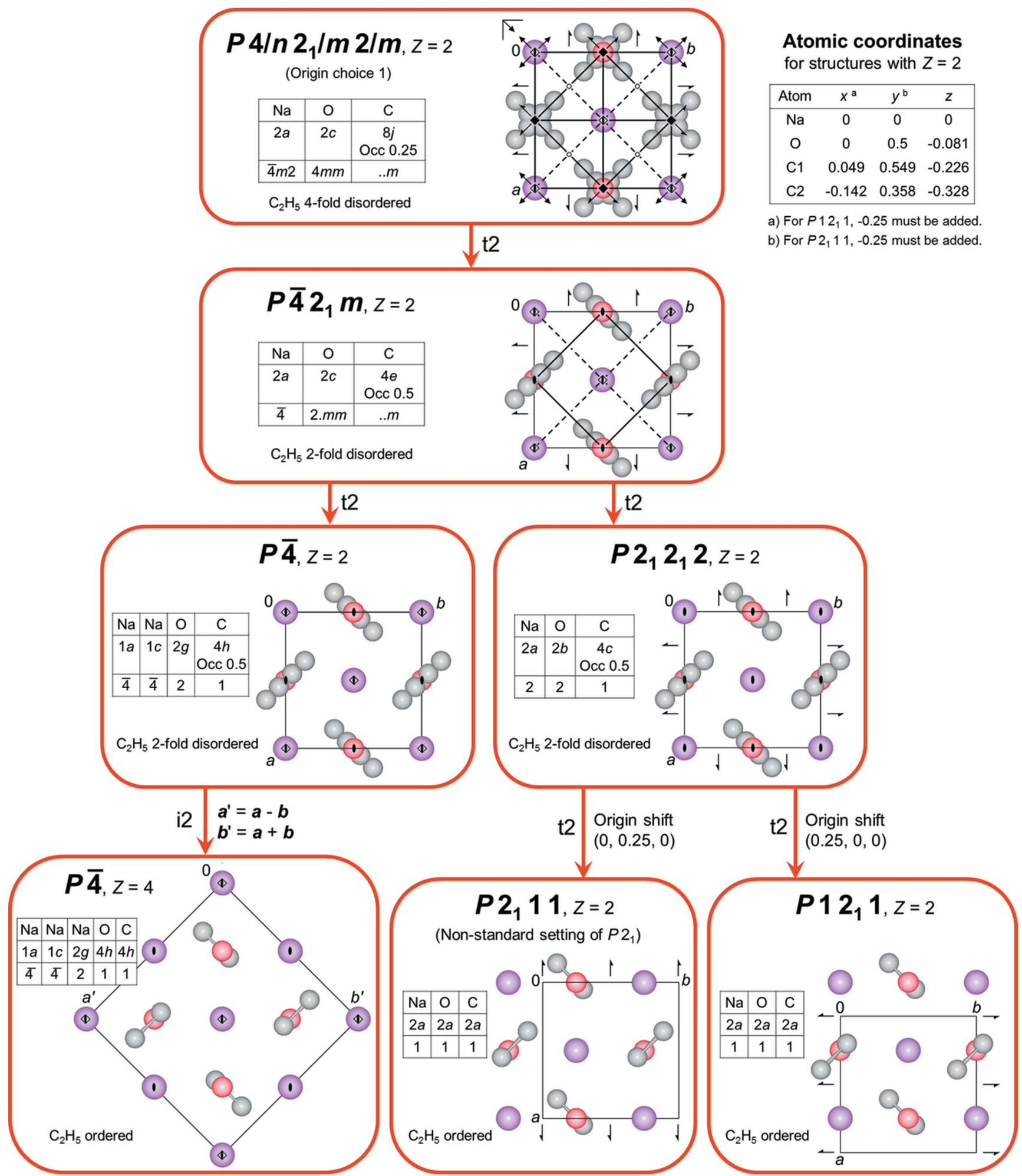

Figure 3

The Bärnighausen tree of NaOEt. Colour key: Na violet, $\mathrm{O}$ red and $\mathrm{C}$ grey. $\mathrm{H}$ atoms have been omitted for clarity. The view direction is [001]. $\mathrm{t} 2$ denotes a translationengleiche subgroup of index two and $\mathrm{i} 2$ an isomorphous subgroup of index two. The small tables give the atom types, Wyckoff positions and site symmetries. Occ denotes the occupancy, if different from one. The experimental crystal symmetry is $P \overline{4} 2_{1} m$, with $Z=2$. 
Table 2

Experimental details for $\mathrm{NaOMe}, \mathrm{NaOEt}, \mathrm{NaO}^{n} \mathrm{Pr}, \mathrm{NaO}^{n} \mathrm{Bu}$ and $\mathrm{NaO}^{n} \mathrm{Am}$.

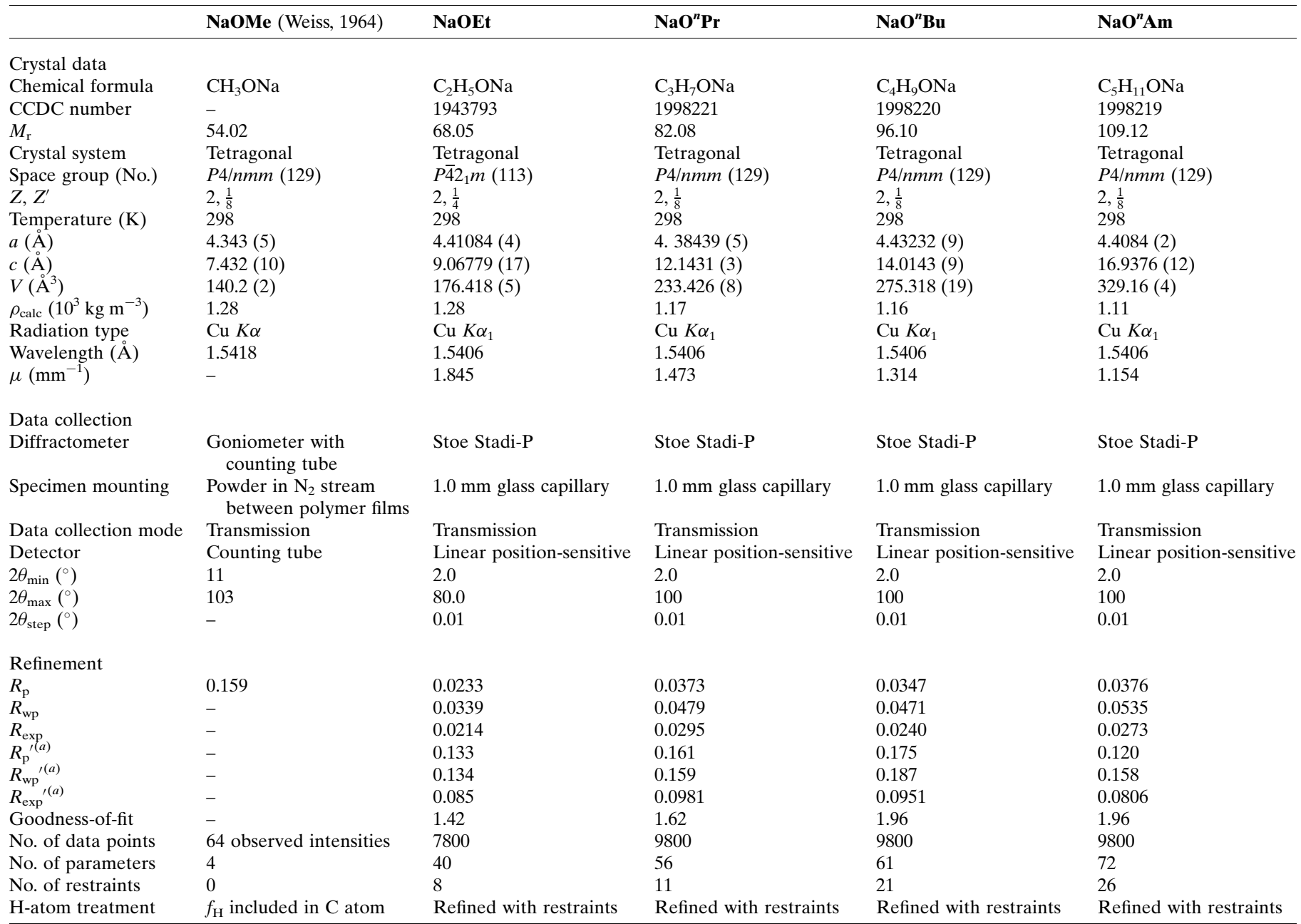

Note: (a) $R_{\mathrm{p}}{ }^{\prime}, R_{\mathrm{wp}}{ }^{\prime}$ and $R_{\text {exp }}{ }^{\prime}$ values are background-corrected data according to Coelho (2018).

A complete ordering of the ethyl groups would require further reduction of symmetry, e.g. to $P \overline{4}$ or $P 2_{1}$. The corresponding Bärnighausen tree (Bärnighausen, 1980; Chapuis, 1992; Müller, 2004, 2006, 2012) is shown in Fig. 3. Such a symmetry reduction would result in a deviation from tetragonal symmetry and/or in a larger unit cell (supercell). Both effects should be clearly visible in the powder pattern. However, the powder pattern of $\mathrm{NaOEt}$ gave no indication of either effect. Hence, the space group is likely to be $P \overline{4} 2_{1} m$.

A transition into a translationengleiche subgoup of index 2 is frequently associated with twinning. Correspondingly, the NaOEt crystals may be twinned, i.e. in one domain the orientation of the ethyl groups is that shown in Fig. $2 b$ and in the other domain the groups are rotated by $90^{\circ}$. However, such a twinning cannot be observed by powder diffraction; hence, it remains unclear if the crystals are actually twinned.

The final Rietveld refinements were carried out in $P \overline{4} 2_{1} m$. No restraints were applied to the $\mathrm{Na}, \mathrm{C}$ and $\mathrm{O}$ atoms. Restraints were only necessary for the $\mathrm{H}$-atom positions. The final Rietveld plot is shown in Fig. 4. Crystallographic data are included in Table 2.
The crystal structure of NaOEt (Fig. $5 b$ ) is similar to the structures of $\mathrm{NaOMe}$ and LiOMe (LiOMe type; Fig. $5 a$ ). The $\mathrm{Na}^{+}$ions form a quadratic net in the (001) plane. The $\mathrm{O}$ atoms are situated in the centre of each mesh 0.734 (3) $\AA$ above or below the plane. The ethyl groups point away from the nets on both sides; hence, they form covering nonpolar layers on both sides of the ionic $\mathrm{Na}-\mathrm{O}$ nets. Subsequent layers are stacked in the [001] direction. This structure can be regarded as an anti$\mathrm{PbO}$ structure. In red $\mathrm{PbO}$ (litharge; Boher et al., 1985), the $\mathrm{Pb}^{2+}$ and $\mathrm{O}^{2-}$ ions form the same net as the $\mathrm{O}$ and $\mathrm{Na}$ atoms in $\mathrm{NaOEt}$, and the lone pairs of the $\mathrm{Pb}^{2+}$ ion in $\mathrm{PbO}$ resemble the positions of the ethyl groups in NaOEt (see Figs. $5 b$ and $5 c$ ).

LiOMe and NaOMe crystallize in the space group $P 4 / \mathrm{nmm}$ $(Z=2)$, with the methyl group on the fourfold axis, which causes no problems, because the shape of the methyl group is close to spherical. In contrast, in NaOEt, the crystal symmetry is reduced to $P \overline{4} 2_{1} m$. Astonishingly, $\mathrm{NaO}^{n} \mathrm{Pr}$ and the higher sodium alkoxides again adopt the higher symmetry $P 4 / \mathrm{nmm}$ $(Z=2)$, with a fourfold disorder of the alkyl groups (see below). This raises the question, why does NaOEt not adopt $P 4 / n m m$ symmetry? An 'intuitive' explanation for the lower 


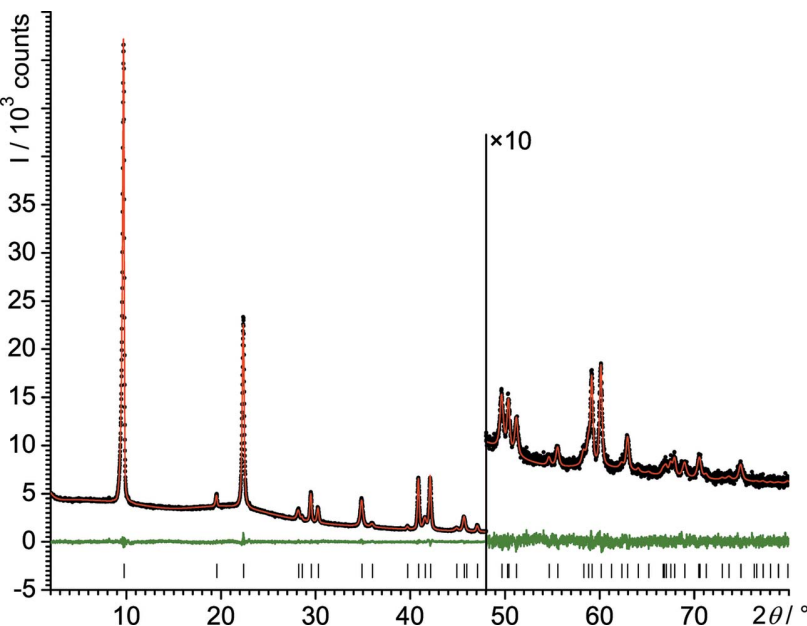

Figure 4

Final Rietveld plot of NaOEt. Experimental data are shown as black dots and simulated data as a red line, with the difference curve in green below. The vertical tick marks denote the reflection positions.

symmetry of NaOEt would be that an ethyl group has a 'less cylindrical' shape than a methyl or propyl group and, hence, avoids being situated on a fourfold axis. The reduced disorder of the ethyl groups of NaOEt in $P \overline{4} 2_{1} m$ leads to a more efficient packing and a higher density. Actually, the density of $\mathrm{NaOEt}$ is $4 \%$ higher than the average density of $\mathrm{NaOMe}$ and $\mathrm{NaO}^{n} \mathrm{Pr}$, both of which crystallize in $P 4 / \mathrm{nmm}$.

3.2. Crystal structures, space group and disorder of $\mathrm{NaO}^{n} \mathrm{Pr}$, $\mathrm{NaO}^{n} \mathrm{Bu}$ and $\mathrm{NaO}^{n} \mathrm{Am}$

Sodium $n$-propoxide $\left(\mathrm{NaO}^{n} \mathrm{Pr}\right)$, sodium $n$-butoxide $\left(\mathrm{NaO}^{n} \mathrm{Bu}\right)$ and sodium $n$-amylate (sodium $n$-pentoxide, $\mathrm{NaO}^{n} \mathrm{Am}$ ) were synthesized from sodium and the corre-

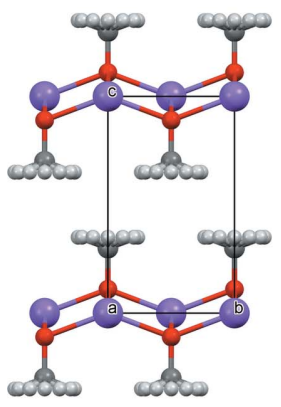

(a)

$\mathrm{NaOMe}$

$\mathrm{P} 4 / \mathrm{nmm}$

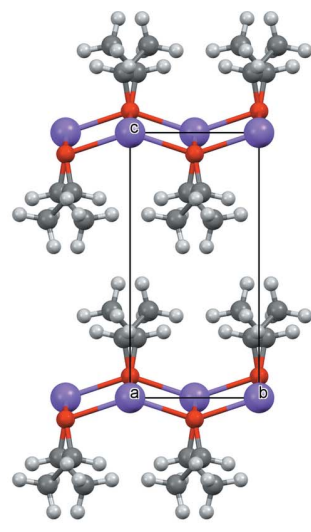

(b)

$\mathrm{NaOEt}$

$P \overline{4} 2{ }_{1} m$

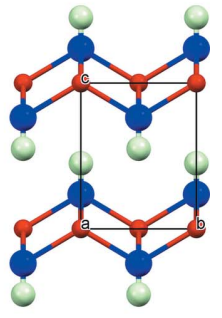

(c)

$\mathrm{PbO}$

$\mathrm{P} 4 / \mathrm{nmm}$
Figure 5

The crystal structures of $(a) \mathrm{NaOMe},(b) \mathrm{NaOEt}$ and $(c) \mathrm{PbO}$ (litharge). Colour key: $\mathrm{Na}$ violet, $\mathrm{O}$ red, $\mathrm{C}$ grey, $\mathrm{H}$ white and $\mathrm{Pb}$ blue. In part $(c)$, the large light-green balls represent the lone pairs of the $\mathrm{Pb}^{2+}$ ions. The view direction is [100]. For a better comparison, the unit cell of $\mathrm{NaOMe}$ was shifted by $\left(0,0, \frac{1}{2}\right)$ with respect to the original data of Weiss (1964) and the $\mathrm{H}$ atoms of $\mathrm{NaOMe}$ were added in calculated positions (with a fourfold disorder). Drawings were made with Mercury (Macrae et al., 2020).
Table 3

Rietveld refinement of $\mathrm{NaO}^{n} \mathrm{Pr}$ in $P 4 / n m m$ and $P \overline{4} 2_{1} m$ under identical conditions, with restraints on the $\mathrm{C}$ and $\mathrm{H}$ atoms.

The values marked by a ' are background-subtracted values. The last column denotes a refinement in $P \overline{4} 2_{1} m$ with two sets of propyl groups, one corresponding to the orientation in $P \overline{4} 2_{1} m$ and the other rotated by $90^{\circ}$, which is occupied in $P 4 / n m m$, but empty in $P \overline{4} 2_{1} m$. N(param) is the number of structural parameters, including the occupancy parameter.

\begin{tabular}{lccc}
\hline & $P 4 / n m m$ & $P \overline{4} 2_{1} m$ & $\begin{array}{l}P \overline{4} 2_{1} m \text { with both } \\
\text { orientations of }{ }^{n} \mathrm{Pr}\end{array}$ \\
\hline$R_{\mathrm{wp}}(\%)$ & 5.424 & 5.654 & 5.386 \\
$R_{\mathrm{wp}}{ }^{\prime}(\%)$ & 17.953 & 18.714 & 17.832 \\
$R_{\mathrm{p}}(\%)$ & 4.198 & 4.376 & 4.238 \\
$R_{\mathrm{p}}{ }^{\prime}(\%)$ & 18.139 & 18.908 & 18.324 \\
Goodness-of-fit & 1.837 & 1.915 & 1.824 \\
$N($ param) & 18 & 18 & $18+1$ (occupancy) \\
Occupancy $p$ & 0.25 (fix) & 0.5 (fix) & $0.38(3): 0.12(3)$ \\
\hline
\end{tabular}

sponding alcohols. Upon evaporation of the alcoholic solutions, the solvates precipitated initially (as a mixture with the solvent-free phases). Further evaporation led to the solventfree forms. The compounds are very sensitive to water; hence, any trace of moisture, also from air, had to be avoided during synthesis, evaporation and PXRD measurements.

The powder diagrams could be easily indexed with tetragonal unit cells, with $Z=2$. The structures were solved by the real-space method and refined by the Rietveld method.

The crystal structures are similar to that of NaOEt (anti$\mathrm{PbO}$ type). In the case of $\mathrm{NaO}^{n} \mathrm{Pr}$, the space group is ambiguous. A refinement in $P \overline{4} 2_{1} m$ with two sets of alkyl groups, as performed for NaOEt, did not yield clear results. The occupancies refined to values of 0.38 (3) and 0.12 (3), which is exactly midway between 0.25 (for $P 4 / \mathrm{nmm}$ ) and 0.5 (for $P \overline{4} 2{ }_{1} m$ ) (see Table 3 ). However, the refinement with one set of alkyl groups gave significantly lower confidence values in $P 4 / n m m$ than in $P \overline{4} 2_{1} m$. For $\mathrm{NaO}^{n} \mathrm{Bu}$ and $\mathrm{NaO}^{n} \mathrm{Am}$, refinements in $P 4 / n m m$ also provided a better fit than in $P \overline{4} 2_{1} m$ (Table 4). Correspondingly, the final refinements of all three compounds were performed in P4/nmm. The final Rietveld plots are shown in Fig. 6. Crystallographic data are included in Table 2. The crystal structures are shown in Fig. 7.

The lattice parameters and the space group of $\mathrm{NaO}^{n} \mathrm{Pr}$ agree with the data determined by Chandran et al. (2006).

The $n$-butyl and $n$-amyl groups are highly disordered, and the electron density is smeared out, especially for the terminal and the next-to-terminal $\mathrm{C}$ atoms. The description of these structures in $P 4 / \mathrm{nmm}$ with fourfold disordered alkyl groups on Wyckoff position $8 j$ is only an approximation of the actual electron density.

We tried to prepare phase-pure powders of solvent-free $\mathrm{NaO}^{i} \mathrm{Pr}$ and $\mathrm{NaO}^{t} \mathrm{Am}$, but the crystal structures could not be solved by PXRD yet. The samples probably contained mixtures of different phases.

\subsection{Solvates}

By crystallization from the corresponding alcohols, we obtained single crystals of four alcohol solvates of sodium alkoxides: $\mathrm{NaOEt} \cdot 2 \mathrm{EtOH}, \mathrm{NaO}{ }^{n} \mathrm{Pr} \cdot 2^{n} \mathrm{PrOH}, \mathrm{NaO}{ }^{i} \mathrm{Pr} \cdot 5^{i} \mathrm{PrOH}$ 
and $\mathrm{NaO}^{t} \mathrm{Am} \cdot{ }^{t} \mathrm{AmOH}$. All of these solvates are sensitive to moisture and air. In a vacuum and under argon (or nitrogen), they decompose into their solvate-free forms. The decomposition is comparably slow for NaOEt.2EtOH, but fast for $\mathrm{NaO}{ }^{i} \mathrm{Pr} \cdot 5^{i} \mathrm{PrOH}$. Correspondingly, the solvates must be stored

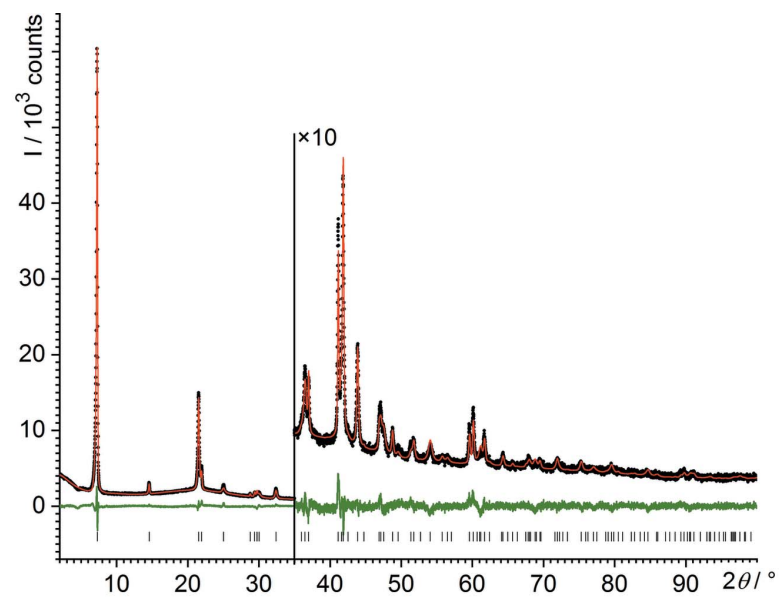

(a)

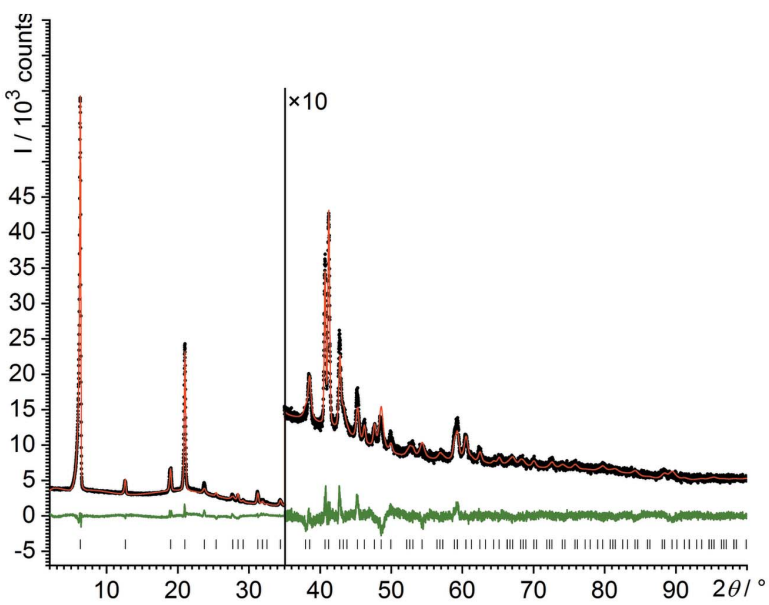

(b)

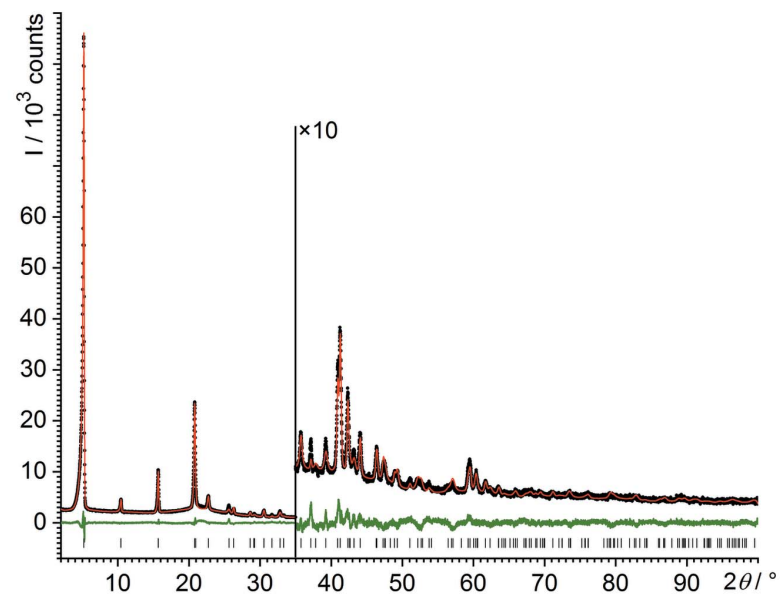

(c)

Figure 6

Final Rietveld plots of $(a) \mathrm{NaO}^{n} \mathrm{Pr},(b) \mathrm{NaO}^{n} \mathrm{Bu}$ and $(c) \mathrm{NaO}^{n} \mathrm{Am}$. Experimental data are shown as black dots and simulated data as a red line, with the difference curve in green below. The vertical tick marks denote the reflection positions.
Table 4

Rietveld refinement of $\mathrm{NaO}^{n} \mathrm{Bu}$ and $\mathrm{NaO}^{n} \mathrm{Am}$ in $P 4 / \mathrm{nmm}$ and $P \overline{4} 2_{1} m$ under identical conditions, with restraints on the $\mathrm{C}$ and $\mathrm{H}$ atoms.

$N$ (param) is the number of structural parameters, including the occupancy parameter.

\begin{tabular}{lccccc}
\hline & \multicolumn{2}{c}{$\mathrm{NaO}^{n} \mathrm{Bu}$} & & \multicolumn{2}{c}{$\mathrm{NaO}^{n} \mathrm{Am}$} \\
\cline { 2 - 3 } & $P 4 / n m m$ & $P \overline{4} 2_{1} m$ & & $P 4 / n m m$ & $P \overline{4} 2_{1} m$ \\
\hline$R_{\text {wp }}(\%)$ & 4.620 & 4.884 & & 5.403 & 5.762 \\
$R_{\text {wp }}(\%)$ & 18.52 & 19.30 & & 15.87 & 17.03 \\
$R_{\mathrm{p}}(\%)$ & 3.578 & 3.766 & & 3.875 & 4.071 \\
$R_{\mathrm{p}}{ }^{\prime}(\%)$ & 18.73 & 19.11 & & 12.44 & 13.13 \\
Goodness-of-fit $[S]$ & 1.924 & 2.032 & & 1.974 & 2.106 \\
$N$ (param) & 23 & 23 & & 28 & 28 \\
\hline
\end{tabular}

in their mother liquor or in the presence of vapours of the corresponding alcohols or kept at low temperature.

The chemical compositions and crystal structures of these four solvates were determined by single-crystal X-ray diffraction. However, there were three obstacles: (i) the mounting of the crystals on the diffractometer was challenging due to their sensitivity to air, moisture, vacuum and dry inert gas; (ii) the crystal quality was limited, especially for $\mathrm{NaO}{ }^{i} \mathrm{Pr} \cdot 5^{i} \mathrm{PrOH}$; (iii) the crystal structures of $\mathrm{NaO}^{n} \mathrm{Pr} \cdot 2^{n} \mathrm{PrOH}$ and $\mathrm{NaO}^{i} \mathrm{Pr} \cdot 5^{i} \mathrm{PrOH}$ are highly disordered. In $\mathrm{NaO}^{n} \mathrm{Pr}$. $2^{n} \mathrm{PrOH}$, the disorder affects all of the propyl groups. In $\mathrm{NaO}{ }^{i} \mathrm{Pr} \cdot 5^{i} \mathrm{PrOH}$, four of the ten ${ }^{i} \mathrm{PrOH}$ units are disordered over two widely separated positions each.

The stability of the solvates of the sodium $n$-alkoxides decreases with increasing chain length. Correspondingly, crystal structures could be determined only for the solvates of $\mathrm{NaOEt}$ and $\mathrm{NaO}^{n} \mathrm{Pr}$, whereas the solvates of $\mathrm{NaO}^{n} \mathrm{Bu}$ and $\mathrm{NaO}^{n} \mathrm{Am}$ are highly instable, poorly crystalline and decompose rapidly, even under cold dry nitrogen.

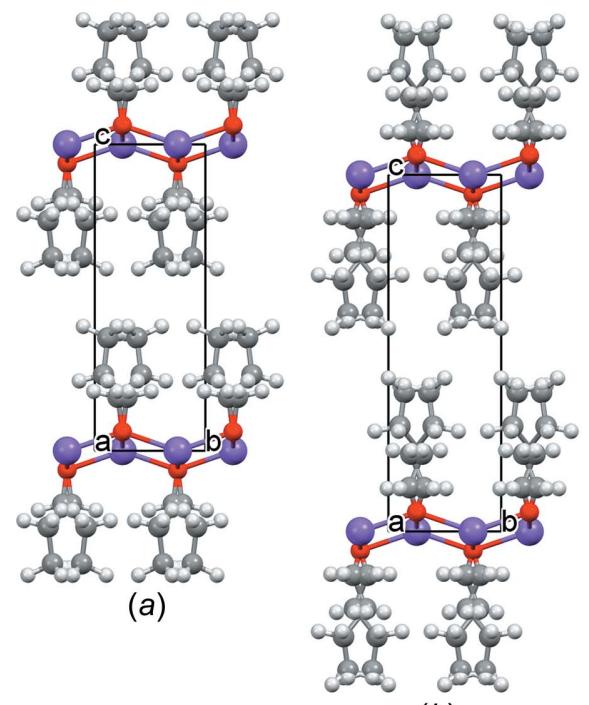

(b)

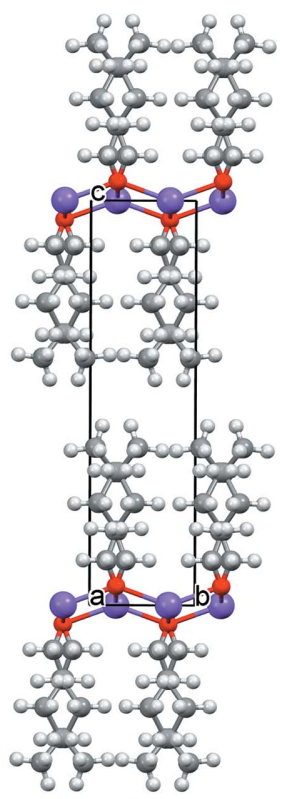

(c)
Figure 7

The crystal structures of $(a) \mathrm{NaO}^{n} \mathrm{Pr},(b) \mathrm{NaO}^{n} \mathrm{Bu}$ and $(c) \mathrm{NaO}^{n} \mathrm{Am}$. Colour key: Na violet, $\mathrm{O}$ red, $\mathrm{C}$ grey and $\mathrm{H}$ white. The view direction is [100]. 
Table 5

Experimental details for the sodium alkoxide solvates.

All determinations were carried out with $\mathrm{Cu} K \alpha$ radiation using a Siemens Bruker three-circle diffractometer with an APEXII detector, an Incoatec I $\mu$ s microfocus source and mirror optics.

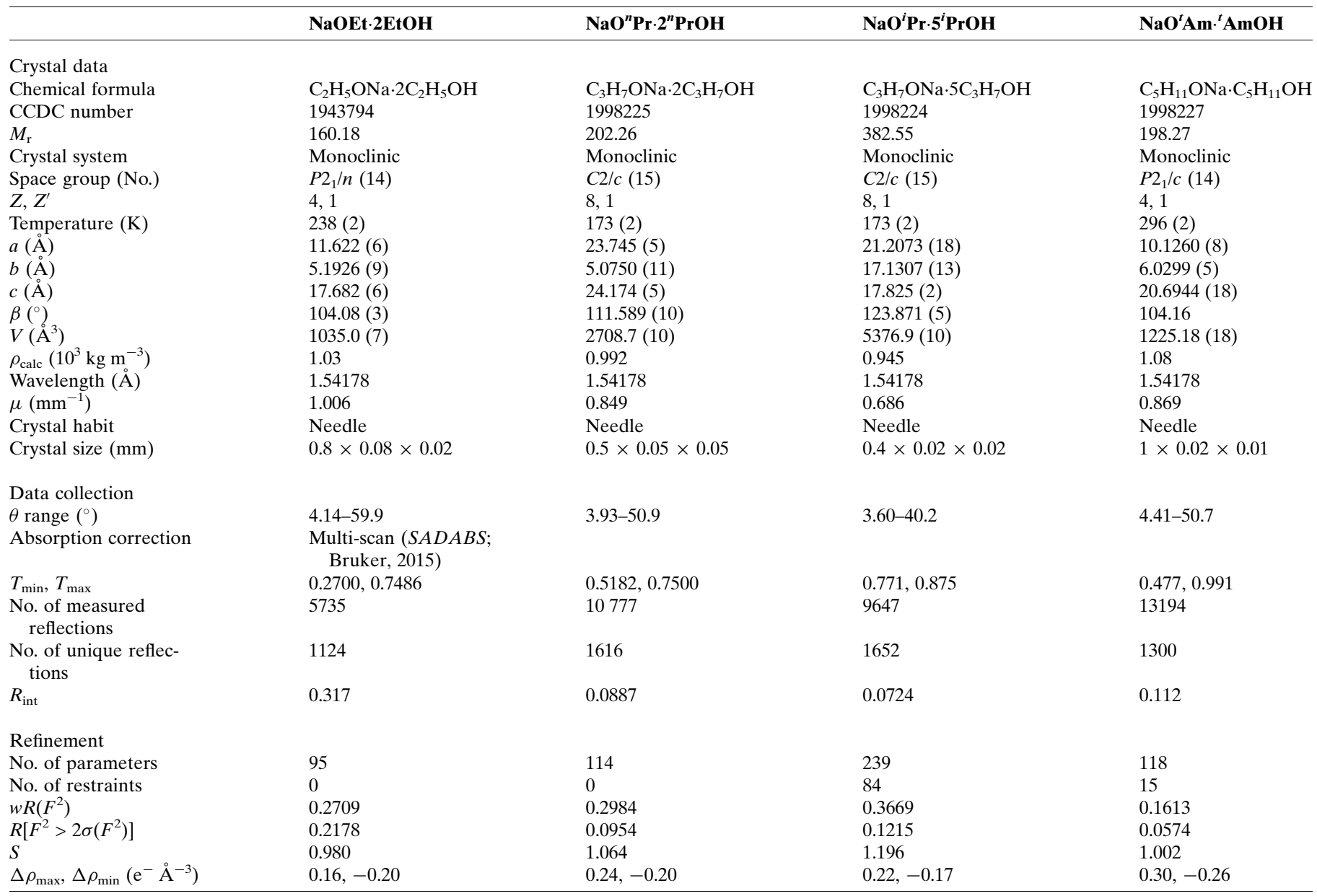

3.3.1. NaOEt.2EtOH and $\mathrm{NaO}{ }^{n} \mathrm{Pr} \cdot 2^{n} \mathrm{PrOH}$. Sodium ethoxide and sodium $n$-propoxide crystallize as needles (see Fig. 8). The single-crystal X-ray analysis (Table 5) revealed the compounds to be disolvates with the composition $\mathrm{NaO} R \cdot 2 R \mathrm{OH}$, as determined by Geuther $(1868 a, b)$ and Frölich (Geuther \& Frölich, 1880). Both solvates are isostructural. The $\mathrm{O}$ atom of

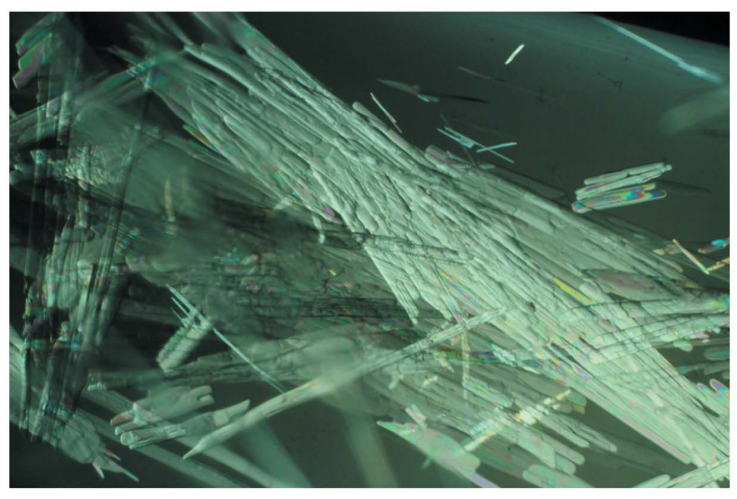

(a) the alkoxide anion $\left(\mathrm{RO}^{-}\right)$bridges two $\mathrm{Na}^{+}$ions, leading to helical $\mathrm{Na}-\mathrm{O}-\mathrm{Na}-\mathrm{O}$ chains. The chains follow a crystallographic $2_{1}$ screw axis. The $\mathrm{Na}^{+}$ions are additionally coordinated to two alcohol molecules $(R \mathrm{OH})$, resulting in a distorted tetrahedral coordination geometry for the $\mathrm{Na}^{+}$ions. In $\mathrm{NaO}^{n} \mathrm{Pr} \cdot 2^{n} \mathrm{PrOH}$, all the propyl groups are disordered and

The crystals of $(a) \mathrm{NaO}^{n} \mathrm{Pr} \cdot 2^{n} \mathrm{PrOH}$ (image width about $15 \mathrm{~mm}$ ) and $(b) \mathrm{NaO}^{t} \mathrm{Am} \cdot{ }^{t} \mathrm{AmOH}$ (image width about $2 \mathrm{~mm}$ ), both in polarized light. 
most of the $\mathrm{C}$ atoms were refined with split positions, with occupancies between 0.40 and 0.60 . The $\mathrm{OH}$ groups of the alcohol molecules form hydrogen bonds to neighbouring $R \mathrm{OH}$ molecules and $R \mathrm{O}^{-}$anions, which additionally stabilize the chains (see Fig. 9). The alkyl groups point outwards. Hence the chains are like tubes, with a polar/ionic inner region and a nonpolar outer region. In the crystal, all the tubes are arranged parallel and form a distorted hexagonal packing (see Fig. 10). However, the space group is different, i.e. $P 2_{1} / c$ for $\mathrm{NaOEt} \cdot 2 \mathrm{EtOH}$ and $C 2 / c$ for $\mathrm{NaO}^{n} \mathrm{Pr} \cdot 2^{n} \mathrm{PrOH}$.

Between the 'tubes' there are only van der Waals contacts between the alkyl groups. This structure explains the observed needle-like morphology of both compounds, with the needle axes parallel to the chain direction [010]. The weak interactions between the 'tubes' allow them to librate around their long axis, which is manifested in the anisotropic displacement parameters of NaOEt-2EtOH (see Fig. 10a). In the case of $\mathrm{NaO}{ }^{n} \mathrm{Pr} \cdot 2^{n} \mathrm{PrOH}$, the limited crystal quality and the disorder

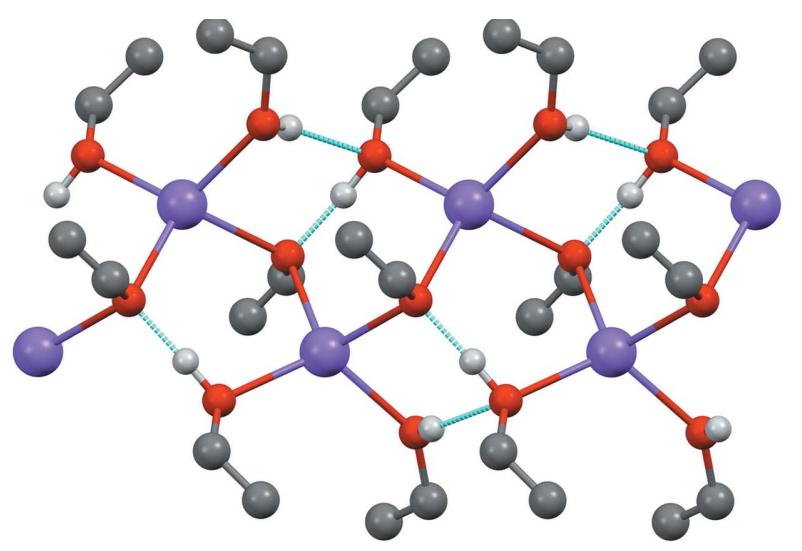

(a)

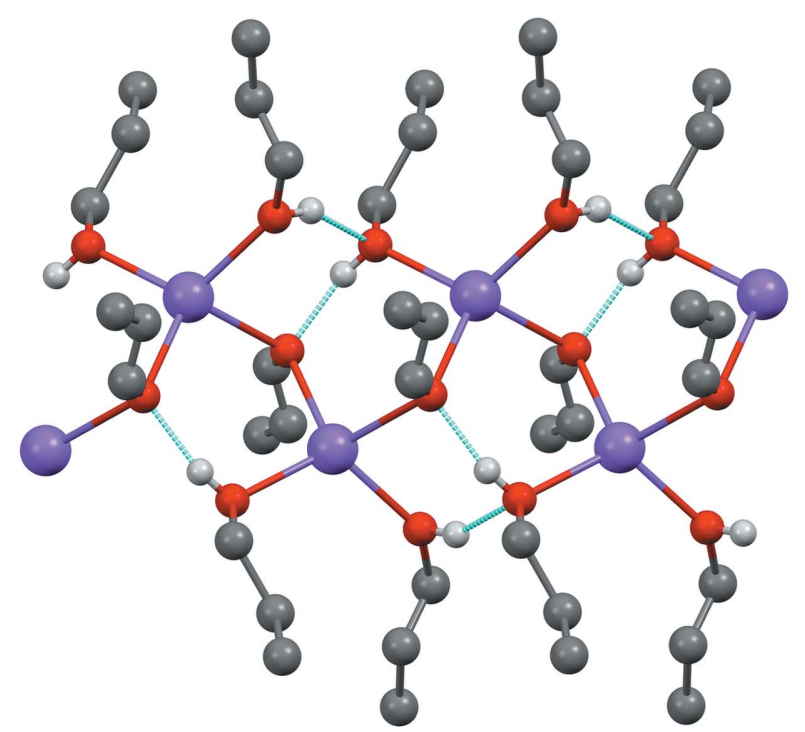

(b)

Figure 9

Helical chains in (a) NaOEt-2EtOH and (b) $\mathrm{NaO}^{n} \mathrm{Pr} \cdot 2^{n} \mathrm{PrOH}$. Colour key: Na violet, $\mathrm{O}$ red, $\mathrm{C}$ grey and $\mathrm{H}$ white. Hydrogen bonds are drawn as dotted light-blue lines. The $\mathrm{H}$ atoms of the alkyl groups have been omitted for clarity. In part $(b)$, the disordered propyl groups are represented by their major-occupied atomic positions only. of the propyl groups prevent an interpretation of the displacement ellipsoids.

The corresponding lithium methoxide solvate, LiOMe. $2 \mathrm{MeOH}$, is a disolvate, like $\mathrm{NaOEt} \cdot 2 \mathrm{EtOH}$ and $\mathrm{NaO}^{n} \mathrm{Pr}$. $2^{n} \mathrm{PrOH}$, but its structure is different. $\mathrm{LiOMe} \cdot 2 \mathrm{MeOH}$ consists of $\mathrm{Li}_{4}(\mathrm{OMe})_{4}(\mathrm{MeOH})_{6}$ tetramers, which are connected through hydrogen bonds via $\mathrm{MeOH}$ molecules to form a twodimensional network. As in NaOEt, the interior layer of this network consists of metal ions and $\mathrm{O}$ atoms, whereas the alkyl groups point outwards. These layers are stacked through van der Waals contacts between the methyl groups only.

3.3.2. $\mathrm{NaO}^{i} \mathrm{Pr} \cdot 5^{i} \mathrm{PrOH}$. Sodium isopropoxide forms a solvate which contains as many as five molecules of isopropanol per $\mathrm{NaO}^{i} \mathrm{Pr}$ unit. Hence, this structure can be regarded as an isopropanol in which one sixth of the protons of the $\mathrm{OH}$ groups are replaced by sodium ions. Correspondingly, the structure of $\mathrm{NaO}^{i} \mathrm{Pr} \cdot 5^{i} \mathrm{PrOH}$ provides an insight into the structure of liquid isopropanol itself.

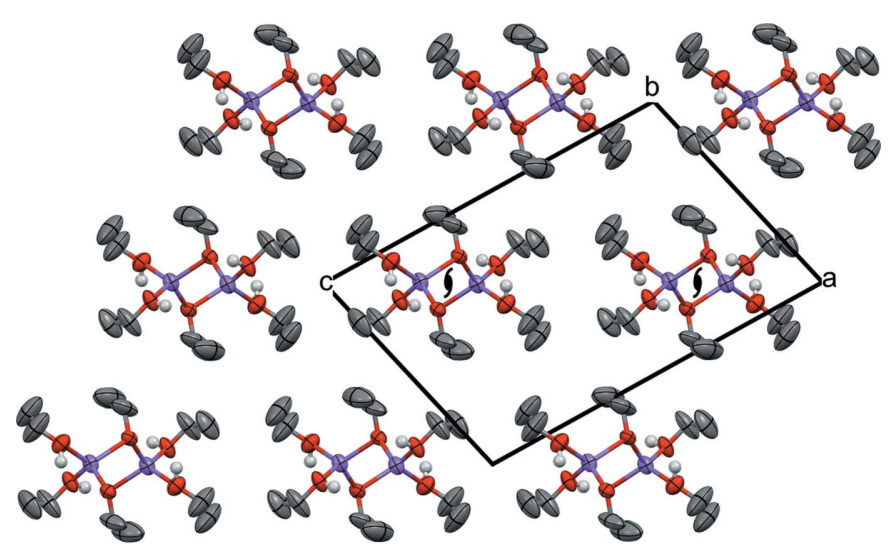

(a)

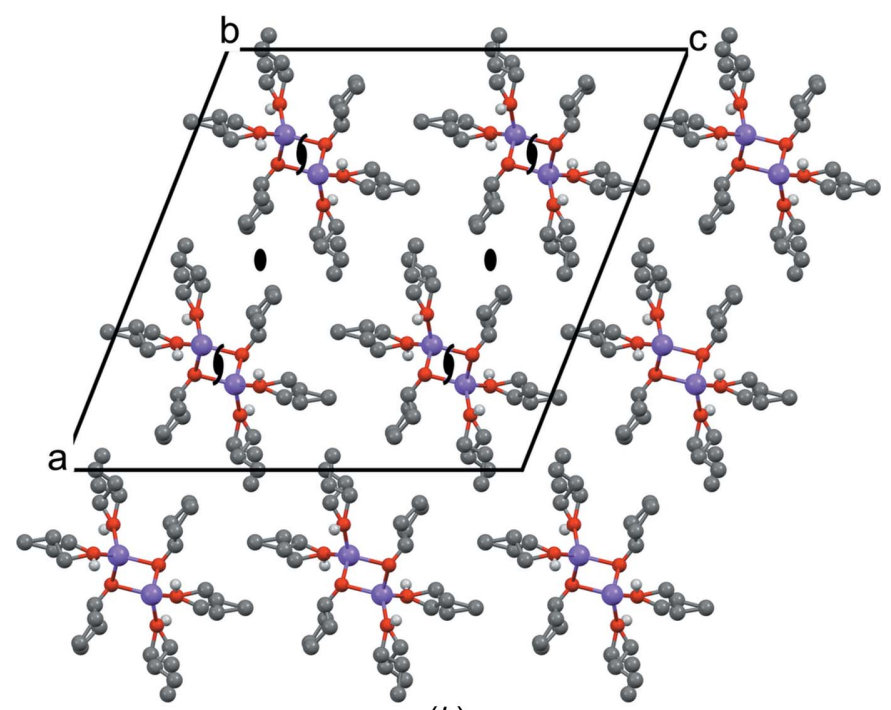

(b)

Figure 10

The crystal structures of (a) NaOEt-2EtOH (space group $P 2_{1} / c$, view direction [010] and displacement ellipsoids at the $50 \%$ probability level) and (b) $\mathrm{NaO}^{n} \mathrm{Pr} \cdot 2^{n} \mathrm{PrOH}$ (space group C2/c, view direction [010]). Selected symmetry elements are shown. In both structures, there is a $2_{1}$ screw axis in the middle of each chain. 
The solvate crystallizes in the space group $C 2 / c$, with $Z=8$. There are two symmetrically independent $\mathrm{Na}^{+}$ions, both on the twofold axis. Each $\mathrm{Na}^{+}$ion coordinates to four $\mathrm{O}$ atoms of ${ }^{i} \mathrm{PrO}^{-}$and ${ }^{i} \mathrm{PrOH}$ moieties (Fig. 11a). The $\mathrm{H}$ atoms of the $\mathrm{OH}$ groups could not be located reliably, as they are probably dynamically disordered. Because of the charge compensation, it is expected that in any instance each $\mathrm{Na}^{+}$cation is surrounded by one ${ }^{i} \mathrm{PrO}^{-}$ligand and three ${ }^{i} \mathrm{PrOH}$ molecules. These $\mathrm{Na}\left({ }^{i} \mathrm{PrO}\right)\left({ }^{i} \mathrm{PrOH}\right)_{3}$ units are connected by further ${ }^{i} \mathrm{PrOH}$ molecules to form a chain along the twofold axis parallel to [010] (see Figs. $11 a$ and 11b). All isopropanol molecules which are not directly coordinated to sodium have an occupancy of 0.5. All isopropyl groups show disorder.

The geometry of the chain is close to $/ 112 / m$ symmetry (rod group No. 11; Kopský \& Litvin, 2010).

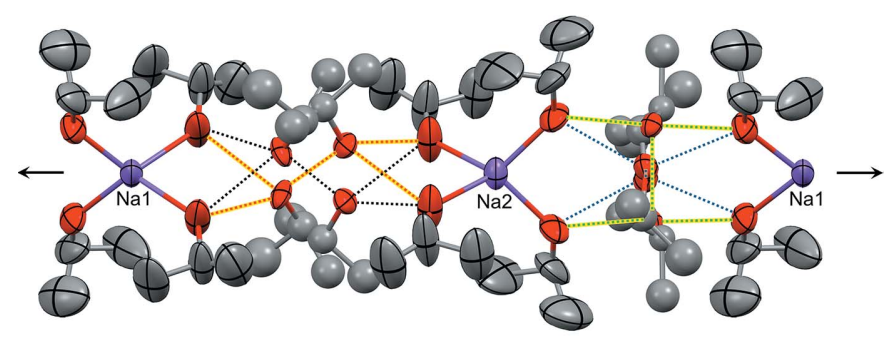

(a)

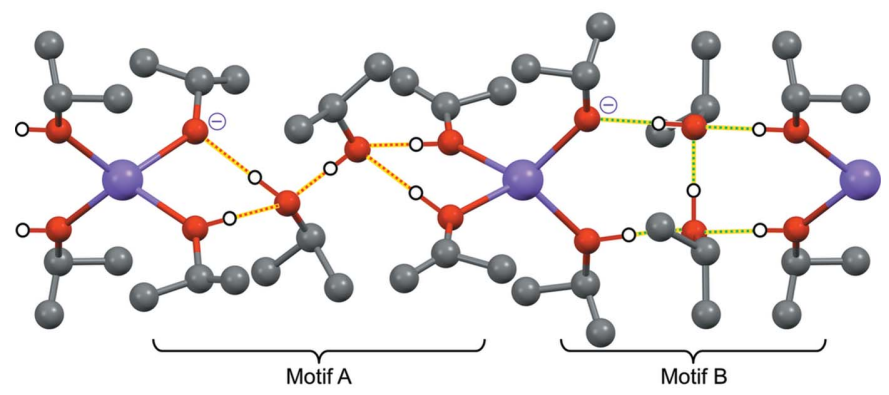

(b)

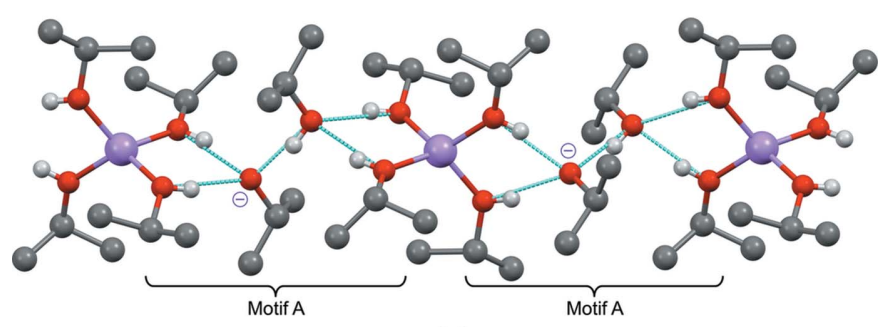

(c)

Figure 11

(a) The crystal structure of $\mathrm{NaO}^{i} \mathrm{Pr} \cdot 5^{i} \mathrm{PrOH}$, showing one chain. The view direction is [001], with the $b$ axis horizontal. Displacement ellipsoids are drawn at the $20 \%$ probability level. All ${ }^{i} \mathrm{PrOH}$ molecules not directly coordinated to Na have an occupancy of 0.5 only. Dotted lines represent the four independent hydrogen-bond networks. The arrows indicate the crystallographic twofold axis. (b) Selected hydrogen-bond networks in $\mathrm{NaO}^{i} \mathrm{Pr} \cdot 5^{i} \mathrm{PrOH}$. (c) The crystal structure of $\mathrm{LiO}^{i} \mathrm{Pr} \cdot 5^{i} \mathrm{PrOH}$. The disorder of the ${ }^{i} \mathrm{Pr}$ groups is not shown. In parts $(b)$ and $(c)$, the $\mathrm{H}$ atoms are shown as white spheres in calculated positions. The H-atom positions shown here represent only one possibility; actually, the $\mathrm{H}$ atoms are disordered and could not be located experimentally. Minus $(-)$ signs denote the anions.
There are four independent hydrogen-bond networks in each chain, each with an occupancy of 0.5 (see Fig. 11a). Two of these networks are shown in Fig. $11 b$.

The hydrogen-bond networks are considerably different from those in pure solid isopropanol. Pure isopropanol forms different hydrogen-bond networks, depending on the experimental conditions: the high-pressure polymorph exhibits eight-membered rings, whereas the low-temperature polymorph forms helical chains with local $3_{1}$ or $3_{2}$ symmetry (see Fig. 12) (Ridout \& Probert, 2014). In contrast, the hydrogenbond network of $\mathrm{NaO}^{i} \mathrm{Pr} \cdot 5^{i} \mathrm{PrOH}$ contains branching between the alcohol molecules, i.e. alcohol molecules are connected by hydrogen bonds to three other alcohol molecules. There are two different topologies, marked as 'Motif A' and 'Motif B' in Fig. 11(b). Motif $\mathrm{A}$ is also present in $\mathrm{LiO}^{i} \mathrm{Pr} \cdot 5^{i} \mathrm{PrOH}$ (Mehring et al., 2002). Motifs A and B can neither be found in other sodium alkoxide solvates nor in the crystal structures of pure isopropanol. In liquid isopropanol, one could expect to find a mixture of all three motifs, namely, rings, chains and branchings.

In $\mathrm{NaO}{ }^{i} \mathrm{Pr} \cdot 5^{i} \mathrm{PrOH}$, the hydrogen-bonded chains are surrounded by the nonpolar isopropyl groups. Between the chains, there are only van der Waals contacts between the isopropyl groups (see Fig. 13). Similarly, in both polymorphs of

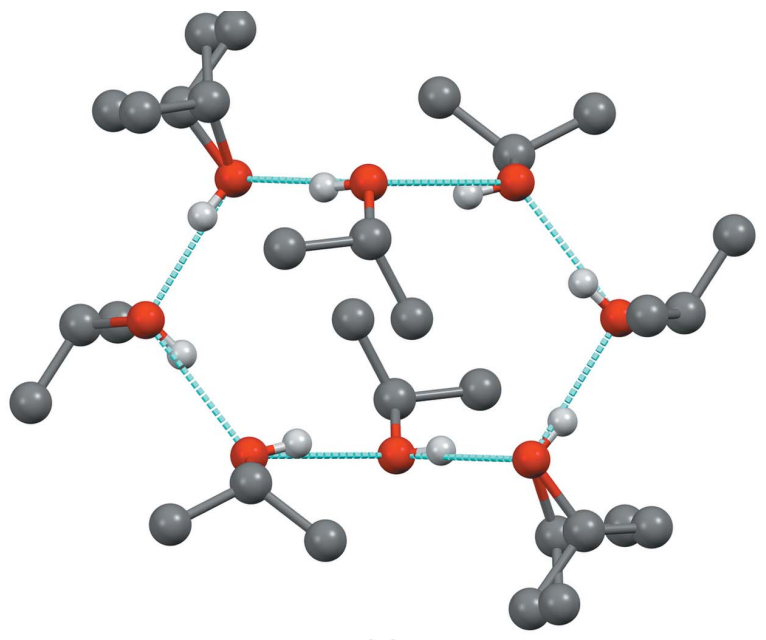

(a)

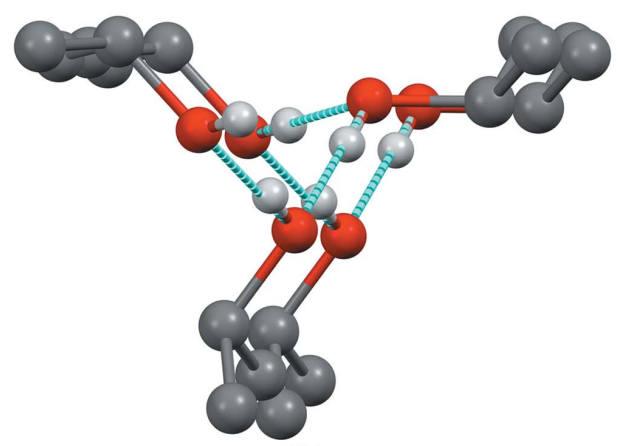

(b)

Figure 12

The hydrogen-bond networks of solid pure isopropanol. (a) Eightmembered ring in the high-pressure phase. (b) Threefold screw axis in the low-temperature phase. In both structures, some of the isopropyl groups are disordered. 
pure ${ }^{i} \mathrm{PrOH}$, the rings and chains have polar surfaces, and are connected to neighbouring rings or chains by van der Waals interactions (see Figs. S1 and S2 in the supporting information).

The chains of $\mathrm{NaO}^{i} \mathrm{Pr} \cdot 5^{i} \mathrm{PrOH}$ are arranged in a distorted hexagonal packing. The packing seems to be similar to the chain packing in $\mathrm{NaO}^{n} \mathrm{Pr} \cdot 2^{n} \mathrm{PrOH}$. The space group is also the same (i.e. $C 2 / c$ ). However, the chains in $\mathrm{NaO}^{i} \mathrm{Pr} \cdot 5^{i} \mathrm{PrOH}$ are situated on a twofold rotation axis, whereas the chains of $\mathrm{NaO}{ }^{n} \operatorname{Pr} \cdot 2^{n} \mathrm{PrOH}$ are placed on a $2_{1}$ screw axis (see Figs. $10 b$ and 13 ).

3.3.3. $\mathrm{NaO}^{t} \mathrm{Am} \cdot{ }^{t} \mathrm{AmOH}$. The $\mathrm{X}$-ray structure analysis revealed that sodium tert-amylate (sodium 2-methyl-2butanolate, $\mathrm{NaO}^{t} \mathrm{Am}$ ) forms a monosolvate with tert-amyl alcohol (2-methyl-2-butanol). In this structure, neighbouring $\mathrm{Na}^{+}$ions are bridged by two ligands in the form of a square. The square shares corners with two other squares, leading to

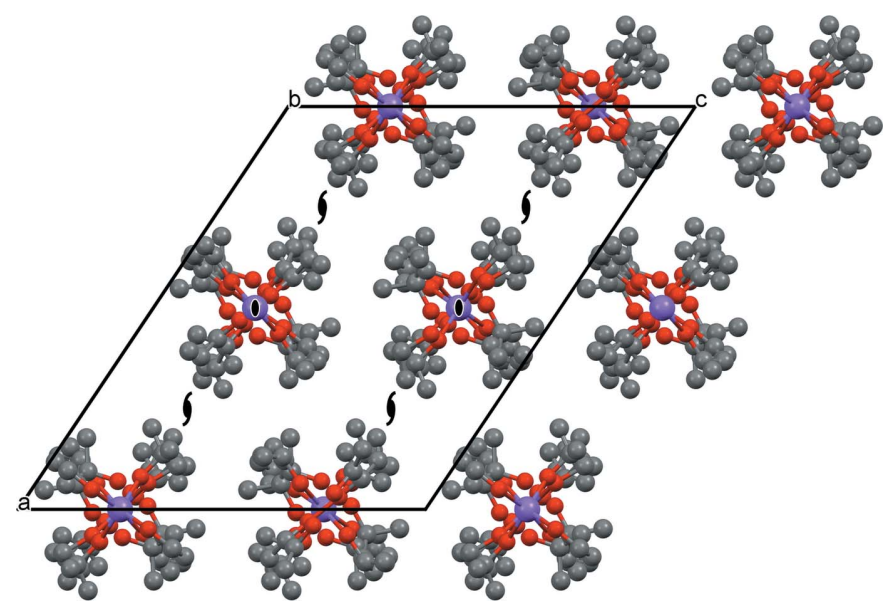

Figure 13

The crystal structure of $\mathrm{NaO} i \mathrm{Pr} \cdot 5^{i} \mathrm{PrOH}$ (space group $C 2 / c$, view along the chains and view direction [010]). The chains are located on twofold rotation axes, in contrast to the $2_{1}$ screw axes for $\mathrm{NaO}{ }^{n} \mathrm{Pr} \cdot 2^{n} \mathrm{PrOH}$ (see Fig. 10b).

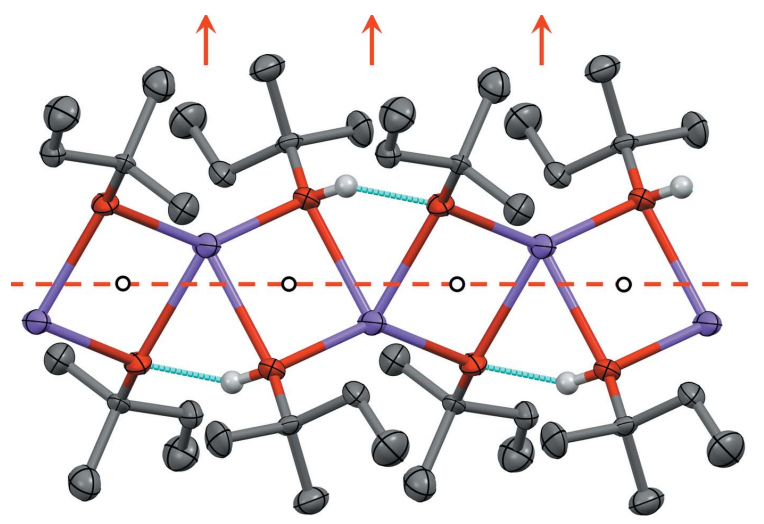

Figure 14

A view of the structure of $\mathrm{NaO}^{t} \mathrm{Am} \cdot{ }^{t} \mathrm{AmOH}$, with displacement ellipsoids drawn at the $50 \%$ probability level. The $\mathrm{H}$ atoms of the tert-amyl groups have been omitted for clarity. The light-blue lines denote the hydrogen bonds. The $\mathrm{H}$ atom is disordered along the hydrogen bond. The black circles represent crystallographic inversion centres. The red symmetry elements represent the approximated local symmetry of the chain (p2/b11).

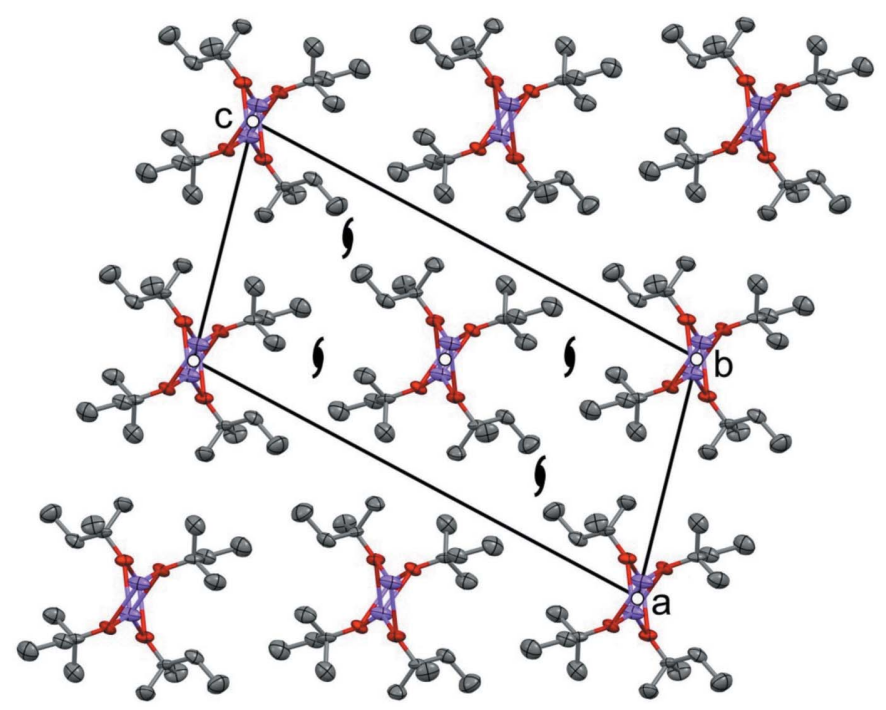

Figure 15

The crystal structure of $\mathrm{NaO}^{t} \mathrm{Am} \cdot{ }^{t} \mathrm{AmOH}$, viewed along the chains (space group $P 2_{1} / n$, view direction [010]), with displacement ellipsoids drawn at the $50 \%$ probability level. Selected symmetry elements are shown.

chains (see Fig. 14). Each square is centred by a crystallographic inversion centre. The squares are additionally connected by hydrogen bonds. The $\mathrm{H}$ atom engaged in this bond is probably disordered, so that in any instance each square contains one ${ }^{t} \mathrm{AmO}^{-}$anion and one ${ }^{t} \mathrm{AmOH}$ ligand, due to electrostatic considerations. The squares form an interplanar angle of $49.8^{\circ}$ only, which is apparently caused by the hydrogen bonds. The tert-amyl groups point outwards, as in the other solvates.

The chain has approximately $/ 2 / b 11$ symmetry, which is a nonstandard setting of $/ 2 / c 11$ (rod group No. 7; Kopský \& Litvin, 2010). In the crystal, only the inversion symmetry is maintained in the space-group symmetry $P 12_{1} / n 1$.

The arrangement of the chains (Fig. 15) is similar to that in $\mathrm{NaOEt} \cdot 2 \mathrm{EtOH}$ (Fig. 10a). The space group is also the same $\left(P 2_{1} / c\right.$, here in the $P 2_{1} / n$ setting). However, in NaOEt.2EtOH, the chains are aligned along the $2_{1}$ axis, whereas in $\mathrm{NaO}{ }^{t} \mathrm{Am} \cdot{ }^{t} \mathrm{AmOH}$, the chains contain inversion centres.

\section{Conclusion}

In this study, we determined the crystal structures of a series of sodium alkoxides $\mathrm{NaO} R\left(R=\mathrm{Et},{ }^{n} \mathrm{Pr},{ }^{n} \mathrm{Bu}\right.$ and $\left.{ }^{n} \mathrm{Am}\right)$ and of a series of solvates of the composition $\mathrm{NaO} R \cdot x R \mathrm{OH}(R=\mathrm{Et}$, ${ }^{n} \operatorname{Pr},{ }^{i} \mathrm{Pr}$ and ${ }^{t} \mathrm{Am} ; x=1,2$ and 5 ). Surprisingly, the crystal structures were unknown. Only the structures of $\mathrm{NaOMe}$, $\mathrm{NaO}^{t} \mathrm{Bu}$ and $\mathrm{NaOMe} \cdot 2 \mathrm{MeOH}$ had been determined previously.

The solvates show a variety of compositions, from the monosolvate $\mathrm{NaO}{ }^{t} \mathrm{Am} \cdot{ }^{t} \mathrm{AmOH}$ via the disolvates $\mathrm{NaO} R \cdot 2 R \mathrm{OH}$ $\left(R=\right.$ Et and $\left.{ }^{n} \mathrm{Pr}\right)$ to the pentasolvate $\mathrm{NaO}{ }^{i} \operatorname{Pr} \cdot 5^{i} \mathrm{PrOH}$. The solvates were obtained from saturated solutions of the alkoxides in the corresponding alcohols. We did not systematically investigate a variation of compositions, temperature and vapour pressure. Presumably, other solvate phases with different compositions may also exist. 
In all the solvated and solvate-free structures, the $\mathrm{Na}^{+}$ion is coordinated in a distorted tetrahedral geometry to four $\mathrm{O}$ atoms. In the solvent-free compounds $\mathrm{NaO} R$, the $\mathrm{O}$ atom has five neighbouring atoms: four $\mathrm{Na}^{+}$ions and the alkyl group. Such a fivefold coordination is quite unusual for organic $\mathrm{O}$ atoms. The $\mathrm{O}$ atoms in organic compounds generally have a maximum of three or four neighbours, when counting counterions, alkyl groups, $\mathrm{H}$ atoms and accepted hydrogen bonds. In most crystal structures of alcohols $R \mathrm{OH}$, the $\mathrm{O}$ atoms have only three neighbours: one alkyl group, one $\mathrm{H}$ atom and one hydrogen bond as acceptor. The overcrowded coordination of the $\mathrm{O}$ atoms in sodium alkoxides is the reason why they so readily form solvates. Already with one additional alcohol molecule, the coordination number of oxygen drops from 5 to 4 , as can be seen in $\mathrm{NaO}^{t} \mathrm{Am} \cdot{ }^{t} \mathrm{AmOH}$. Any additional alcohol molecule increases the number of threefold-coordinated $\mathrm{O}$ atoms. This stabilization is reflected in the thermal stability of the solvates: to obtain the solvent-free alkoxides, NaOEt. $2 \mathrm{EtOH}$ must be heated at ambient pressure to about $200{ }^{\circ} \mathrm{C}$ and $\mathrm{NaO}^{n} \mathrm{Pr} \cdot{ }^{n} \mathrm{PrOH}$ even to about $220^{\circ} \mathrm{C}$ (Geuther \& Frölich, 1880 ). In contrast to sodium alkoxides, the sodium alkanoates $R \mathrm{COO}^{-} \cdot \mathrm{Na}^{+}$and sulfonates $R \mathrm{SO}_{3}{ }^{-} \cdot \mathrm{Na}^{+}$rarely form solvates with alcohol or $R \mathrm{COOH}$ molecules. There, the higher number of $\mathrm{O}$ atoms provides a sufficient number of donor atoms for the coordination of the $\mathrm{Na}^{+}$ion, even with higher coordination numbers of $\mathrm{Na}^{+}$, e.g. 6 in $\mathrm{CH}_{3} \mathrm{COO}^{-} \cdot \mathrm{Na}^{+}$(Dittrich et al., 2018) or 6-7 in $\mathrm{CH}_{3} \mathrm{SO}_{3}{ }^{-} \cdot \mathrm{Na}^{+}$(Wei \& Hingerty, 1981).

Four different topologies are present in sodium alkoxides: the alkoxides with linear alkyl chains $\left(R=\mathrm{Me}, \mathrm{Et},{ }^{n} \mathrm{Pr},{ }^{n} \mathrm{Bu}\right.$ and ${ }^{n} \mathrm{Am}$ ) form layers of $\mathrm{Na}^{+}$and $\mathrm{O}^{-}$atoms, $\mathrm{NaO}^{t} \mathrm{Bu}$ forms clusters (hexamers and nonamers), $\mathrm{NaOMe} \cdot 2 \mathrm{MeOH}$ forms tetramers, which are connected by hydrogen bonds into layers, and the other solvates form chains of differing composition. In all cases, polar and nonpolar regions are clearly separated: the interior of the layers, clusters and chains consist of $\mathrm{Na}^{+}$and $-\mathrm{O}^{-}$ions and is held together by electrostatic forces, whereas the outer regions are composed of the nonpolar alkyl groups. Neighbouring layers, clusters or chains are connected by van der Waals contacts only. As a result, the chain structures of all the solvates form needles. $\mathrm{NaO}^{t} \mathrm{Bu}$ forms prisms or cubes. For the layer structures of $\mathrm{NaO} R$, a plate-like morphology could be expected.

The compound $\mathrm{NaO}{ }^{i} \mathrm{Pr} \cdot 5^{i} \mathrm{PrOH}$ differs from pure isobutanol only by the substitution of every sixth proton of an $\mathrm{OH}$ group with a sodium cation. The crystal structure exhibits a complicated chain structure with branched hydrogen bonds between the isopropanol molecules. Such branchings are not present in the crystal structures of pure isopropanol, but give an interesting insight into the structural diversity of liquid isopropanol.

\section{Acknowledgements}

The authors thank Daniel Kratzert (Albert Ludwigs University, Freiburg) for his kind assistance with the refinement of the disordered alkyl groups of $\mathrm{NaO}^{i} \mathrm{Pr} \cdot 5^{i} \mathrm{PrOH}$, Ulrich Müller (Philipps University, Marburg) for helpful suggestions for improvement of the Bärnighausen tree, Edith Alig (Goethe University, Frankfurt) for the measurement of numerous powder diagrams, Lothar Fink (Goethe University, Frankfurt) for support with the single-crystal structure determination and excellent maintenance of all of our diffractometers, Tanja Reipen (Clariant, Frankfurt) for providing information on industrial sodium tert-amylate, and Trixi Cronje for assistance with the correction of the English. Open access funding enabled and organized by Projekt DEAL.

\section{References}

Aroyo, M. I. (2016). International Tables for Crystallography, Vol. A, Space-group Symmetry, 6th ed. Chester: International Union of Crystallography.

Bärnighausen, H. (1980). MATCH Commun. Math. Comput. Chem. 9, 139-175.

Beske, M., Tapmeyer, L. \& Schmidt, M. U. (2020). Chem. Commun. 56, 3520-3523.

Blanchard, J.-M., Bousquet, J., Claudy, P. \& Letoffe, J.-M. (1976). J. Therm. Anal. 9, 191-203.

Boher, P., Garnier, P., Gavarri, J. R. \& Hewat, A. W. (1985). J. Solid State Chem. 57, 343-350.

Boultif, A. \& Louër, D. (1991). J. Appl. Cryst. 24, 987-993.

Bruker (2015). APEX3. Bruker AXS GmbH, Karlsruhe, Germany.

Chandran, K., Nithya, R., Sankaran, K., Gopalan, A. \& Ganesan, V. (2006). Bull. Mater. Sci. 29, 173-179.

Chapuis, G. C. (1992). Symmetry relationships between crystal structures and their practical application, in Modern Perspectives in Inorganic Chemistry, edited by E. Parté, pp. 1-16. Dordrecht: Kluwer Academic Publishers.

Coelho, A. A. (2018). J. Appl. Cryst. 51, 210-218.

David, W. I. F., Shankland, K., van de Streek, J., Pidcock, E., Motherwell, W. D. S. \& Cole, J. C. (2006). J. Appl. Cryst. 39, 910915.

Davies, J. E., Kopf, J. \& Weiss, E. (1982). Acta Cryst. B38, 2251-2253.

Dittrich, B., Bergmann, J., Roloff, P. \& Reiss, G. J. (2018). Crystals, 8, 213-224.

Friedrich, H., Guth, J., Schweinzer, J., Letzelter, T. \& Bender, H.-J. (1999). European Patent EP 1086067 B1.

Geuther, A. (1859). Justus Liebigs Ann. Chem. 109, 71-79.

Geuther, A. (1868a). Jena. Z. Med. Naturwiss. 4, 16-18.

Geuther, A. (1868b). Jena. Z. Med. Naturwiss. 4, 241-263.

Geuther, A. \& Frölich, O. (1880). Justus Liebigs Ann. Chem. 202, 288-331.

Greiser, T. \& Weiss, E. (1977). Chem. Ber. 110, 3388-3396.

Hahn, T. (2005). Editor. International Tables for Crystallography, Vol. A, Space-group symmetry, 5th ed., with corrections. Chester: International Union of Crystallography.

Hofmann, D. W. M. (2002). Acta Cryst. B58, 489-493.

Hunger, K. \& Schmidt, M. U. (2018). In Industrial Organic Pigments, 4th ed. Weinheim: Wiley-VCH.

Kopský, V. \& Litvin, D. B. (2010). Editors. International Tables for Crystallography Vol. E, Subperiodic groups, 2nd ed. Chester: International Union of Crystallography.

Laar, B. van \& Schenk, H. (2018). Acta Cryst. A74, 88-92.

Lescoeur, H. (1895). C. R. Acad. Sci. 121, 691-692.

Liebig, J. (1837). Ann. Pharm. 23, 12-42.

Loopstra, B. O. \& Rietveld, H. M. (1969). Acta Cryst. B25, 787-791.

Macrae, C. F., Sovago, I., Cottrell, S. J., Galek, P. T. A., McCabe, P., Pidcock, E., Platings, M., Shields, G. P., Stevens, J. S., Towler, M. \& Wood, P. A. (2020). J. Appl. Cryst. 53, 226-235.

Mehring, M., Berkei, M. \& Schürmann, M. (2002). Z. Anorg. Allg. Chem. 628, 1975-1978.

Müller, U. (2004). Z. Anorg. Allg. Chem. 630, 1519-1537. 
Müller, U. (2006). In Inorganic Structural Chemistry, 2nd ed., ch. 18. Weinheim: Wiley-VCH.

Müller, U. (2012). In Symmetriebeziehungen zwischen verwandten Kristallstrukturen. Anwendungen der Gruppentheorie in der Kristallchemie. Wiesbaden: Vieweg+Teubner Verlag. [English translation: Symmetry Relationships between Crystal Structures (2013), Oxford University Press.]

Nekola, H., Olbrich, F. \& Behrens, U. (2002). Z. Anorg. Allg. Chem. 628, 2067-2070.

Østreng, E., Sønsteby, H. H., Øien, S., Nilsen, O. \& Fjellvåg, H. (2014). Dalton Trans. 43, 16666-16672.

Ridout, J. \& Probert, M. R. (2014). CrystEngComm, 16, 7397-7400.
Sheldrick, G. M. (2015a). Acta Cryst. A71, 3-8.

Sheldrick, G. M. (2015b). Acta Cryst. C71, 3-8.

Wanklyn, J. A. (1869). Ann. Chem. Pharm. 150, 200-206.

Wei, C. H. \& Hingerty, B. E. (1981). Acta Cryst. B37, 1992-1997.

Weiss, E. (1963). Helv. Chim. Acta, 46, 2051-2054.

Weiss, E. (1964). Z. Anorg. Allg. Chem. 332, 197-203.

Weiss, E. \& Alsdorf, H. (1970). Z. Anorg. Allg. Chem. 372, 206213.

Wheatley, P. J. (1961). J. Chem. Soc. (London), 1961, 4270-4274.

Wondratschek, H. \& Müller, U. (2010). International Tables for Crystallography, Vol. A1, Symmetry Relations between Space Groups, 2nd ed. Chester: International Union of Crystallography. 